\title{
Molecular Imprinting Technology for Biomimetic Assemblies
}

\section{Biomimetik Sistemler için Moleküler Baskılama Teknolojisi}

\author{
Nilay Bereli ${ }^{\oplus}$, Semra Akgönüllü ${ }^{\oplus}$, Sevgi Aslıyüce ${ }^{\oplus}$, Duygu Çimen ${ }^{\circledR}$, Ilgım Göktürk ${ }^{\odot}$, \\ Deniz Türkmen ${ }^{\bullet}$, Handan Yavuz ${ }^{\odot}$ and Adil Denizli* ${ }^{*}$ \\ Hacettepe University, Department of Chemistry, Beytepe, Ankara, Turkey.
}

\section{ABSTRACT}

\begin{abstract}
The term biomimetic can be simply defined as the examination of nature. The scientist inspired from the enormous diversity of nature to solve human problems or facilitate the daily life by mimicking natural models, systems and elements especially in biomedical and therapeutic applications to make better drugs, artificial organs, sensing instruments etc. Biological recognition elements like proteins, antibodies, enzymes, DNA, lectins, aptamers, cells and viruses have been heavily used to ensure specificity in such applications in spite of their lack of stability and reusability. However, in the last two decades molecularly imprinted polymers, MIPs, have been synthesized as an alternative to mimic natural biological interactions for a broad spectrum of templates by means of coordinating functional monomers around template in the presence of crosslinker. This review will outline the broad contours of biomimetics prepared by molecular imprinting techniques and their practical applications in the separation techniques, tissue engineering applications, biomimetic surfaces, sensors, artificial membranes and drug delivery systems.
\end{abstract}

\section{Key Words}

Molecular imprinting, biomimetic, separation, sensing, polymer brushes, artificial membranes, drug delivery, tissue engineering.

\section{öz}

iyomimetik terimi, kısaca doğanın incelenmesi olarak tanımlanabilir. Bilim adamları biyomedikal ve terapötik uygulamalarda, daha iyi ilaçlar, yapay organlar, algılama aletleri vb. yapmak için doğal modelleri, sistemleri ve unsurları taklit ederek, insan sorunlarını çözmek ve günlük yaşamı kolaylaştırmak için doğanın muazzam çeşitliliğinden ilham aldılar. Bu tür uygulamalarda, stabilite ve tekrar kullanılabilirlikteki eksikliklere rağmen, özgüllüğü sağlamak için proteinler, antikorlar, enzimler, DNA, lektinler, aptamerler, hücreler ve virüsler gibi biyolojik tanıma öğeleri yoğun olarak kullanılmıştır. Bununla birlikte, son yirmi yılda moleküler baskılanmış polimerler (MıP'ler), çapraz bağlayıcının varlığında kalıp yapı etrafında fonksiyonel monomerlerin koordine edilmesi yoluyla geniş bir örnek yelpazesi oluşturmuş ve doğal biyolojik etkileşimleri taklit etmeye bir alternatif olarak sentezlenmiştir. Bu derleme, ayırma tekniklerinde, doku mühendisliği uygulamalarında, biyomimetik yüzeylerde, sensörlerde, yapay membranlar ve ilaç taşınım sistemlerinde moleküler baskılama teknikleriyle hazırlanan biyomimetiklerin genel hatlarını ve pratik uygulamalarını özetleyecektir.

\section{Anahtar Kelimeler}

Moleküler bakılama, biomimetik, ayırma, analiz, polimer fırçalar, yapay membranlar, ilaç salınımı, doku mühendisliği. 


\section{INTRODUCTION}

Treco he life is mainly based on a crucial term: molecular recognition. Various functions of living systems, such as enzymes, proteins, antibodies, nucleic acids and cell signaling actualize via molecular recognition. Molecular recognition consists of the specific design of various non-covalent interactions such as ionic attractions, hydrogen bonding, van der Waals forces, hydrophobic effect and so on [1]. In the development of technology, the structures and operating mechanisms of systems in nature have been inspired. Human innovation by imitating nature is called "biomimetic" or "biomimicry" and many of the products used in daily life, industry, military etc. have been developed by the biomimetic approach. Molecular imprinting technology is based on a biomimetic strategy allowing synthetic or semi-synthetic materials to imitate the molecular recognition seen in natural systems [2,3]. Synthetic materials having a capacity of artificial recognition based on molecular imprinting technology go back to Dickey's research in 1955
[4]. Dickey modified silica materials with some organic dyes including methyl orange and its homologs, by acidifying silica solutions of these dyes in to produce selective adsorbents. When we come to the 1970s, Wulff et al. introduced the main concept of molecular imprinting technology which is still valid today [5]. This approach was based on covalent bonds between template molecule and functional monomers. In 1981, Arshady and Mosbach introduced a non-covalent approach which is the most popular method today [6]. It relies on a prearrangement of functional monomers with the template before polymerization via non-covalent interactions. In general, molecular imprinting polymers (MIPs) are produced via polymerization process of functional monomers and crosslinkers in the presence of the template molecule. In MIPs, the selective recognition of the target analyte is provided by the tailored-made architecture of the cavities embedded in the polymer matrix. Formation of these specific and selective cavities consists of three stages (Figure 1):
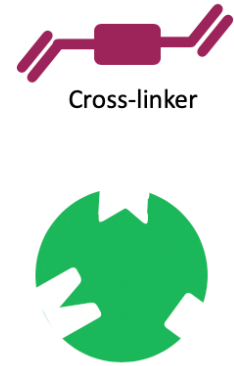

Template

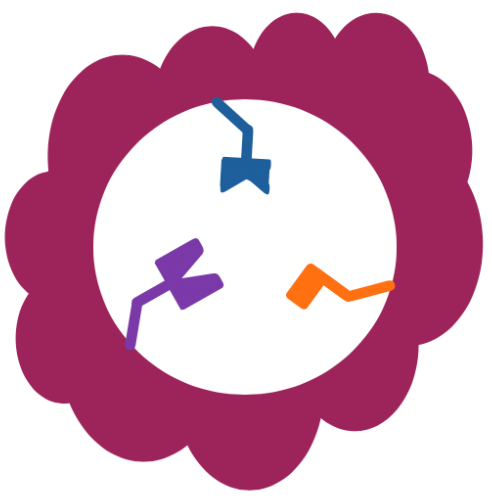

Imprinted polymer

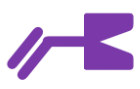

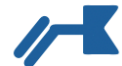

Self-assembly

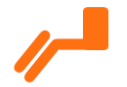

Functional monomers

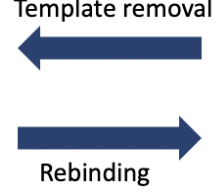

Rebinding
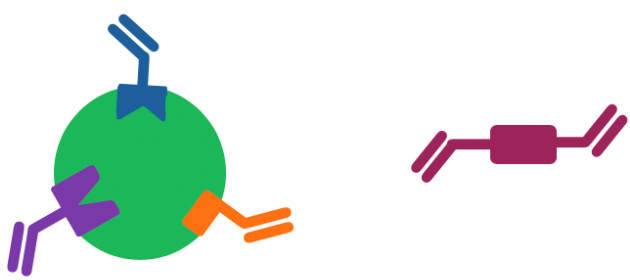

Polymerization

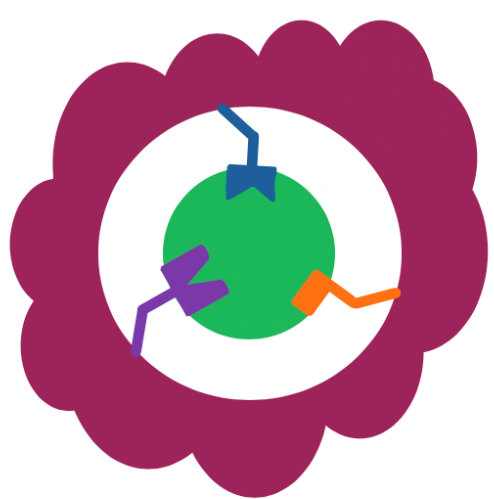

Figure 1. General steps of molecular imprinting technology. 
- Self-assembly of selected functional monomers around the template molecule

- Polymerization of the functional monomers crosslinking agent in the presence of template molecule porogens

- Template removal step resulting in target-specific cavities.

MIPs can recognize the analytes that conform to the shape and size of imprinted molecular cavities. Molecular imprinting technology enables to synthesize target-specific polymers that can recognize biological compounds such as amino acids, proteins, peptides, or nucleotides, and also chemicals such as drugs, food additives and pollutants. MIPs can be synthesized in a various shape and size including bulk materials, dendrimers, and micro- and nanoparticles. MIPs can be divided four main approaches with respect to interaction type between functional monomers and template molecule: (i) covalent imprinting, (ii) semi-covalent imprinting, (iii) non-covalent imprinting and (iv) metal ion coordination mediated imprinting. Because of its outstanding features such as easy production, low-cost, reusability, mechanical and chemical stability, molecular imprinting technology has been attracted in a wide range of fields including separation and purification studies, biosensors, catalysts, drug delivery systems and so on [7-10].

\section{Molecular Imprinting Techniques for Biomimetics}

\subsection{Separation Techniques}

Molecular imprinting technology is widely utilized in separation techniques which can be classified as sample pretreatment and chromatographic separation of biomolecules, pharmaceuticals, environmental pollutants such as heavy metals and phenolic compounds. For instance, MIPs can be prepared by mimicking antibodies in order to purify target antigens. The stationary phase prepared using MIPs is more robust and stable, showing resistance for harsh conditions temperature, $\mathrm{pH}$ and organic solvents compared with immunoaffinity stationary phases. Moreover, the cost of the stationary phase with MIPs is lower and its shelf life will be longer due to its high stability.

Recently, molecularly imprinted nanostructures as biomimetics of natural antibodies were synthesized [11]. Cardiac Troponin I is a protein of 209 amino acids and molecular weight of about 23 kDa. Cardiac Troponin I, a case protein, was chosen for its high diagnostic value in acute coronary syndromes. For this aim, idiotipic peptide of Troponin I was used as a template molecule and highly crosslinked poly(acrylamide-co-methacrylic acid) nanoparticles (NPs) were prepared via precipitation polymerization. The effect of monomer ratio to

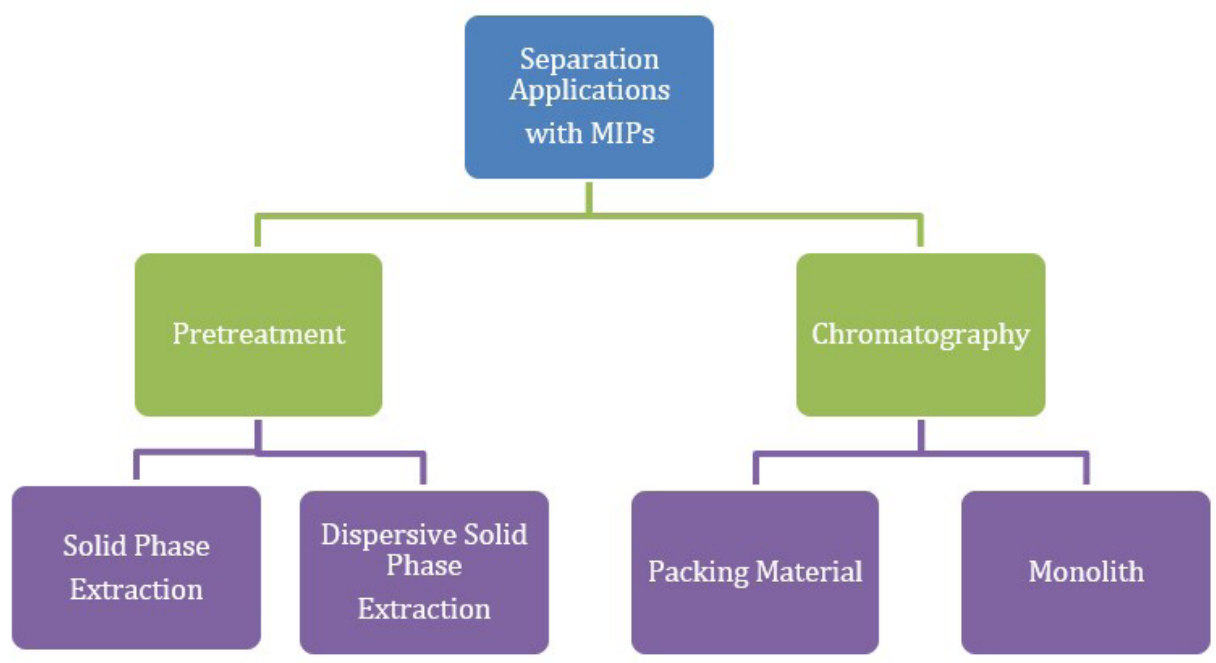

Figure 2. General classes of separation application methods using MIPS. 
template on the formation of the binding sites were investigated. The maximum imprinting efficiency was found in the range of 175:1-437:1.

Enantiomeric pharmaceuticals have a diverse effect on living organisms. Ofloxacin, a new kind fluorinated quinolone, is a broad-spectrum antibiotic commonly used for treating bacterial infections. S-ofloxacin is 8-128 times stronger in preventing the growth of gram bacteria than R-ofloxacin, and almost two times more active than the racemic ofloxacin $[12,13]$. Molecularly imprinted magnetic NPs as tunable stationary phase were also integrated in a microfluidic device for enantioseparation by capillary electrochromatography [14]. The NPs were fabricated by co-polymerization of methacrylic acid and ethylene glycol dimethacrylate on silane-functionalized magnetic NPs in the presence of S-ofloxacin as the template molecule. The characterization of the imprinted magnetic NPs was studied with thermal gravimetric analysis, transmission electron microscope and infrared spectroscopy. Separation studies of ofloxacin enantiomers were optimized by the composition and $\mathrm{pH}$ of mobile phase, the separation voltage and varying the packing length of nanoparticles zone.

Peng et al. prepared photonic-magnetic responsive molecularly imprinted microspheres (PM-MIMs) by seed polymerization for selective extraction of $17 \beta$-estradiol (17 $\beta$-E2) from real samples [15]. The PM-MIMs have $\mathrm{Fe}_{3} \mathrm{O}_{4}$ core, $\mathrm{SiO}_{2}$ middle layer, and MIPs shell showing photo-responsive properties. Maximum adsorption capacity and binding kinetics of PM-MIMs towards $17 \beta-E 2$ were found to be $0.84 \mathrm{mg} / \mathrm{g}$ and $26.08 \mathrm{mg} / \mathrm{L}$, respectively. Moreover, PM-MIMs exhibit photo-responsive properties: $45.0 \%$ of $17 \beta-E 2$ was released from the PM-MIMs at $365 \mathrm{~nm}$ irradiation, and $94.0 \%$ of the released $17 \beta-E 2$ was rebound to the PM-MIMs at $440 \mathrm{~nm}$. In another study, a new chiral stationary phase was improved by grafting molecularly imprinted nanoparticles (MINPs) onto silica beads [16]. Two kind of synthesis procedure, i.e. solid-phase imprinting and precipitation polymerization were investigated and the second one successful for exhibiting efficient chiral selectors. MINPs with an average size of $249.0 \mathrm{~nm}$ were synthesized using itaconic acid as functional monomer and ethylene dimethacrylate as cross-linking agent. This new stationary phase showed a good capability in resolving the racemate of the antidepressant drug citalopram and also separating its major metabolites, i.e. (+)-(S)-desmethylcitalopram and (+)-(S)-didesmethylcitalopram, by liquid chromatography.
Molecularly imprinted cryogel columns were produced for selective aflatoxin extraction from food samples [17]. Because of their outstanding feature, i.e. mimicking natural antibodies, aflatoxin subtypes B1, B2, G1, and G2 imprinted cryogels are named as multiclonal plastic antibodies. The cryogels were characterized by Fourier transform infrared (FTIR) spectroscopy, scanning electron microscopy (SEM), and spectrofluorimetry. Selectivity of the imprinted cryogels were studied using ochratoxin A and aflatoxin M1 as competing agents and imprinting efficiency of the imprinted cryogels were found to be 1.84 and 26.39 against ochratoxin A and aflatoxin $M 1$, respectively. Optimal conditions of the imprinted cryogels for aflatoxin extraction were found to be $25 \mathrm{ng} / \mathrm{mL}$ for each species, $0.43 \mathrm{~mL} / \mathrm{min}, 7.0,30^{\circ} \mathrm{C}$, and $200 \mathrm{mg}$ for concentration, flow rate, temperature, and embedded particle, respectively. Another artificial antibody example is reported as immunoassay to catch clenbuterol which is a sympathomimetic amine widely used as a bronchodilator and decongestant in clinical management and a growth promoter in animal production [18]. In this study, semi-covalent imprinting method was used to improve the specificity of MIP artificial antibody. After the polymerization process, the template molecule was splited by hydrolysis and removed by methanol/acetic acid solution. Rebinding of template molecule was accomplished via hydrogen bond interaction. The linear range for clenbuterol was found to be $10^{-5}$ to $1000 \mu \mathrm{g} / \mathrm{L}$, with a detection limit of $10^{-7} \mu \mathrm{g} / \mathrm{L}$.

Recently, nanocomposite-incorporated molecularly imprinted membranes inspired from the biomimetic polydopamine (pDA)-based self-polymerization method, were developed for the selective adsorption and separation of tetracycline [19]. Tetracycline binding capacity was found to be $67.43 \mathrm{mg} / \mathrm{g}$ and rebinding stability was calculated as $93 \%$ of the saturated binding capacity after 11 cycling binding/desorption cycles. In another study, molecularly imprinted organosilanol polymer synthesized for specific uptake of creatinine [20]. Matrix of siloxane bonds was obtained from polycondensation of hydrolyzed tetraethoxysilane (TEOS) and utilized as functional monomer while doped aluminum ion $\left(\mathrm{Al}^{3+}\right)$ and creatinine were employed as cross-linker and template molecule, respectively. Maximum binding capacity of MIPs towards creatinine were found to be $17.4 \mathrm{mg} / \mathrm{g}$ polymer. Selectivity studies were also applied and binding selectivities were calculated as 3.90 and 4.17 for creatine and N-hydroxysuccinimide, respectively. 
Antibodies are utilized in various biotechnological and biomedical areas including diagnostic and therapeutic agents. Therefore, it is significant to purify and obtain antibodies with high yield. In literature, various studies have been reported for separation, isolation and purification of antibodies. Bereli et al. prepared a new imprinted material for IgG purification from human plasma. For this aim, they imprinted Fc fragment into poly(hydroxyethyl methacrylate) cryogel matrix for the oriented immobilization of anti-hlgG [21]. Anti-hlgG immobilized non-imprinted poly(hydroxyethyl methacrylate) cryogels were also prepared as a control group. The amount of immobilized anti-hlgG were $19.8 \mathrm{mg} / \mathrm{g}$ and $23.7 \mathrm{mg} / \mathrm{g}$ for non-imprinted and imprinted cryogel columns, respectively. Imprinted cryogel column exhibited much higher adsorption capacity $(86.9 \mathrm{mg} / \mathrm{g})$ than the non-imprinted one $(29.7 \mathrm{mg} / \mathrm{g})$. Moreover, elution was accomplished up to $96.7 \%$ of IgG purity using $1.0 \mathrm{M}$ $\mathrm{NaCl}$. Another molecularly imprinted cryogel was produced for purification of human interferon-alpha which are proteins exhibiting antiviral, anti-proliferating and immunomodulatory activities, from human gingival fibroblast culture [22]. At optimum conditions, maximum adsorption capacity was found to be $254.8 \times 10^{4} \mathrm{IU} / \mathrm{g}$ from aqueous solution. Specific activity of the purified interferon $\alpha-2 b$ on HeLa cell line was determined between $3.45 \times 10^{8} \mathrm{IU} / \mathrm{mg}$ and $3.75 \times 10^{8} \mathrm{IU} / \mathrm{mg}$.

\subsection{Tissue Engineering Applications}

The tissue engineering has offered as an alternative area to tissue transplantation or tissue organ. The growing scaffolds that mimic the structure of tissue is one of the greatest challenges in the field of the tissue engineering. The tissue engineering applications make use of biomaterials and cells in combination to restore, maintain or develop tissue function. The approaches of the tissue engineering has been improved to establish artificial tissues mimicking natural ones with cells and the different types scaffolds (such as natural and synthetic polymers scaffolds) [23]. The most important speciality of these polylactide (PLA), polyglycolide (PGA) and polylactide-co-glycolide (PLGA) scaffolds is biocompatible and biodegradable. The tissue engineering is a broad field of science. The tissue engineering involves scientific areas such as medicine, chemistry, life science, cell biology, molecular biology, material science and engineering. In recent years, the tissue engineering approaches are investigated a protein molecular imprinting method to create bioactive scaffolds with molecular recognition. The polymer biomaterials (such as collagen, alginate, chitosan and silk) are used for the tissue engineering applications. In addition, cryogels used as potential tissue scaffolds for regenerative medicine owing to their extensive desired characteristics including porosity, mechanical integrity and swelling reswelling kinetics [24]. The bio-macromolecules are based a great important role in the healing process for tissue engineering applications. The scaffold-based bottom-up strategies on the development of the bioactive scaffolds for cell culture systems or implantation are investigates in the tissue engineering approaches. The produced scaffolds with molecular imprinting method are capable of adsorbing and selectively recognizing macromolecule within a mixture of biological compounds in the injury site.

Nanotechnology is used in the tissue engineering applications. Rosellini et. al. have been synthesized and characterized of molecular imprinted polymers with recognition properties for a laminin peptide sequence [25]. The prepared scaffold structures are used as functionalized structures in the development of bioactive materials for the tissue engineering application. These nanoparticles were synthesized with precipitation polymerization as the template of methacrylic acid and as the cross linking of trimethylpropane trimethacrylate. The cytotoxicity tests were performed in contact with the imprinted nanoparticles. These tests were showed a normal vitality of $\mathrm{C} 2 \mathrm{C} 12$ myoblasts cultured in the medium. The preliminary in vitro cell culture tests with C2C12 myoblasts were performed to evaluate the biocompatibility of the molecular imprinted polymeric films to used cell adhesion, proliferation, differentiation and suggesting.

The gaining control over cell growth and adhesion is used applied cell biology, in micro scale biosensor fabrication and a high throughput cell-based screening as well as tissue engineering. The control over cell growth and adhesion is provided by imitating small molecule or macromolecule reagents with affinity for a cell surface receptor onto a non adhesive surface. Small molecule and macromolecule reagents are often susceptible to enzymatic or environmental degradation. These molecule reagents preparation and purification increases the complexity of surface fabrication and cost. The cell growth and adhesion are important the cell surface topology. The tissue engineering a surface with well-defined topology typically requires expensive and/or specialized equipment and/or multistep processes such as microcontact printing. 
In this study, DePorter et. al. prepared the cell imprinted features on the surface of a polyacrylamide hydrogel [26]. Hydrogels are ideal substrates for cell growth in the context of the tissue engineering applications. Hydrogels are inexpensive and easy to prepare. It is not cytotoxic and permeable to oxygen and other soluble factors. Hydrogels have a tunable mechanical property. DePorter et. al. investigated a technique to prepare substrates for programmed cell adhesion and growth. The experimental results demonstrated that the cell imprinted polyacrylamide hydrogels is a straight forward method and inexpensive for cell growth and adhesion.

Thalassemia is an inherited blood disease. The disease has two forms, minor and major. Thalassemia minor is asymptomatic. The symptomatic form of thalassemia is major. The only treatment of disease is frequently and consistently blood transfusions. It seems iron overload in the host with blood transfusion. Molecularly imprinted cryogels have an universality, stability, simplicity and cheapness of the scaffolds. Aslıyüce et. al. prepared $\mathrm{Fe}^{3+}$ ions imprinted supermacroporous cryogel for the removal of iron from the plasma of the patients with iron overload [27]. In the first step, $\mathrm{Fe}^{3+}$ ions were complexed with $\mathrm{N}$-methacryloyl-(L)-cysteine (MAC) and the $\mathrm{Fe}^{3+}$ ions imprinted poly(hydroxyethyl methacrylate-Nmethacryloyl-(L)-cysteine) poly(HEMA-MAC) cryogels were synthesized by bulk polymerization using methylen bis-acrylamide as crosslinker and ammonium persulfate-tetramethyl ethylene diamine as initiator. After that, the template ( $\mathrm{Fe}^{3+}$ ions) were removed using $0.1 \mathrm{M}$ EDTA solution. The specific surface area of cryogel was found to be $32.7 \mathrm{~m}^{2} / \mathrm{g}$. A maximum $\mathrm{Fe}^{3+}$ ions adsorption capacity of poly(HEMA-MAC) cryogels was observed 75 $\mu \mathrm{g} / \mathrm{g}$ polymer.

The majority of protein imprinted polymer studies are usually used for model macromolecules like an ovalbumin, lysozyme (Lyz), bovine serum albumin (BSA), hemoglobin $(\mathrm{Hb})$, and fibronectin (Fn) for tissue engineering technologies [28]. The molecular imprinting of proteins can confirm the tissue engineering applications. Gao et al. prepared molecular imprinted polymer (MIP) system conjugated with chitosan and alginate of a magnetite $\left(\mathrm{Fe}_{3} \mathrm{O}_{4}\right)$ nanoparticles-based system for molecular recognition of ovalbumin [29]. The imprinting effect with the mass ratio (1:2) was showed to be dependent on the alginate to chitosan exhibiting the best adsorption capacity and the imprinting efficiency values to ovalbumin. This prepared molecular imprinted system was showed a highly selective specialty for different template molecules such as hemoglobin, bovine serum albumin, ovalbumin and lysozyme. Hawkins et al. optimized a template removal system using molecular imprinted polyacrylamide gel using sodium dodecylsulfate and acetic acid for a bovine hemoglobin ( $\mathrm{Hb})$ [30]. In this study, investigated an enzymatic digestion based template removal system with trypsin. In spite of a SDS:AcOH ratio of $10 \%(\mathrm{w} / \mathrm{v}): 10 \%(\mathrm{v} / \mathrm{v})$ didn't show a highest template removal percentage (only 47.6\%). However, these results show that the highest imprinting efficiency is (>90\%). If the agents begin to support conformational changes on the imprinting matrix, a higher template removal percentage can result in lower imprinting efficiencies. Additionally, Hawkins et al. was tested an enzymatic digestion based template removal system with trypsin and showed an even higher template removal capacity $87.4 \%$. These experimental results showed a significantly lower imprinting efficiency $20.4 \%$.

Circular dichroism (CD) is a spectroscopic technique for studying protein secondary structures. Bovine serum albumin (BSA) used a typical protein template in molecular imprinted polymers. The CD is used to clearly showed the negative impact on the overall of bovine serum albumin (BSA). Kryscio et al. investigated the CD to analyze conformational changes in bovine serum albumin (BSA) on the different functional monomers [31]. In this study, different functional monomers (such as 3-aminophenylboronic acid, acrylamide, methacrylic acid, $\mathrm{N}$-isopropyl acrylamide and acrylic acid) and cross linkers (such as ethylene glycol dimethacrylate and $\mathrm{N}, \mathrm{N}^{\prime}$-methylenebisacrylamide) used for the CD to analyze conformational changes. According to the results, this study demonstrated that these reactants induced significant changes in the secondary structure of the template protein.

The bioactive scaffolds are used to mimic the in vivo cellular microenvironment in tissue engineering applications. Vozzi et. al. developed the combination of soft lithography technology and molecular imprinting to enhance cellular adhesion and to guide cell growth [32]. The gelatin is an adhesion protein. They used the gelatin which was imprinted of polymeric scaffolds for cellular tests. In this study, polymethylmethacrylate (PMMA) scaffolds was prepared by poly(dimethylsiloxane) (PDMS) microstructures molds imprinted with TRITClectin and FITC-albumin. These polymeric surfaces were 
characterized with Fourier transform infrared spectrophotometer (FTIR) and contact angle measurements. The prepared bioactive scaffolds were used for the cell growth and proliferation. The cell culture experiments were investigated on cell and molecularly imprinted PMMA microstructures [32].

Chitosan is used to improve mechanical properties of polymeric scaffolds with molecular imprinting method. Guo et al. developed several studies focusing on chitosan based matrices for bovine hemoglobin $(\mathrm{Hb})$ recognition for tissue engineering applications [33]. Chitosan is water soluble and can be combined with epichlorhydrin as a cross linker. The important characteristic of chitosan is preserved the cationic amine function. That are used as a matrix for acrylamide monomers in the molecular imprinting process. Guo et al. studied a chemical modification of porous chitosan beads with adding maleic anhydride groups to develop chitosan bonding to acrylamide (AAm). The chemical modification increased vertical growth of poly(acrlyamide) (PAAm) chains from the surface of the porous chitosan beads.

Hydrogels are polymer scaffolds with crosslinked and three-dimensional hydrophilic polymer networks and are generally used in tissue engineering applications. Xia et al. developed hemoglobin imprinted semi-interpenetrating polymer network in an aqueous medium with chitosan and acrylamide (AAm) [34].

Chitosan is an alkaline polysaccharide containing of hydroxyl and amino functional groups. Chitosan has important properties such as biodegradation, hydrophilicity, biocompatibility and non-toxic. It is used in the food, medicine, metal recovery, water treatment, biochemical, biomedical and tissue engineering. Dan et. al. investigated the different copolymerization systems for chitosan and other synthetic polymers at different temperatures and $\mathrm{pH}$ values for the recognition of ovalbumin [35]. In this study, molecularly printed polymers (MIPs) were prepared by using ovalbumin as template molecules. The prepared gels were characterized by using zeta meter, Fourier transform infrared spectroscopy (FTIR) and field emission scanning electron microscope. The effect of different kinds of functional monomers was optimized and compared. In this study, the cross linking agent was N,N-methylenebisacrylamide and investigated the influence of the synthesis temperature. The adsorption isotherms of the chitosan imprinted gels fitted by a Langmuir model. The maximum adsorption capacities $\left(Q_{\max }\right)$ found to be $9.74 \mathrm{mg} / \mathrm{g}$ for the MIP (CS-g-AAm) and $22.94 \mathrm{mg} / \mathrm{g}$ for the MIP (CSg-MAA).

In regenerative medicine applications, the bioactive scaffolds can be used to mimic an in vivo cellular microenvironment is a challenge. Criscenti et. al. fabricated a soft molecular imprinted electrospun bioactive scaffold for tissue engineering [36]. The scaffolds were prepared using different growth factors and proteins onto the surface in different polyesters. The scaffolds were bound a selectively each of the different proteins. The soft molecular imprinting method allowed fabricating high affinity binding sites on electrospinning fibers compared to non imprinted polymers. The imprinting of electrospinning fibers with several growth factors followed in a significant effect on cell behavior. These scaffolds were used in a cell free approach to steer endogenous tissue engineering applications.

\subsection{Artificial Membranes}

The main uses of artificial membranes are blood and wastewater treatment via dialysis, ultrafiltration, microfiltration and reverse osmosis methods. The necessity of developing membrane technology, which is frequently and successfully used in the industrial field, for specific treatments and purification has emerged. The use of synthetic membranes has been inspired by the selective permeability of biological membranes. Considering that the molecular imprinting technology mimics the antigen/antibody, hormone/receptor and enzyme/ substrate interactions, synthetic membranes and molecular imprinting technology can be used together as a mimic of biological system. In recent years, these two methods are used together in many areas such as tissue engineering, genomics proteomics application, drug delivery, biomedical applications, and most often in the food industry and waste water treatment systems.

Overabundant antibiotic exposure causes bacterial resistance. Therefore, wastes containing antibiotics are an important environmental problem. Tetracyclines are a broad-spectrum antibiotic that affects both gram (-) and gram (+) bacteria, which is often used by veterinary medicine. Some of the antibiotics in the body of the animals do not decompose and are left to the environment with animal wastes. Wu et al., a polydopamine assisted metal-organic method on $\mathrm{Al}_{2} \mathrm{O}_{3}$ ceramic porous membranes imprinted tetracycline. The tetracycline adsorp- 
tion capacity of imprinted membranes was found to be $35 \mathrm{mg} / \mathrm{g}$. After 10 consecutive bindings with the same membrane, the adsorption capacity decreased by only $9 \%$, and the prepared materials were reusable, which is one of the most important features of molecular imprinted materials [37].

Although estradiol is the natural hormone of women, it becomes an environmental pollutant when drugs and hormone supplementing drug wastes are introduced into the water. These substances are called endocrine disrupters. Non-natural exposure can lead to adult reproductive impairment, developmental disorders in children and breast cancer. Koç et al. synthesized poly hydroxyethyl metacrylate (PHEMA)/ethylene glycol dimethacrylate (EGDMA) particles in which estradiol was used as a template molecule and prepared composite polymers by embedding them in PHEMA cryogel membranes. The maximum binding capacity of the imprinted cryogels was about $5 \mathrm{mg} / \mathrm{g}$ of the polymer. Cholesterol and stigmasterol were selected as competing agents because of their similar structures with estradiol. The selectivity of the estradiol imprinted cryogels were approximately 85 times greater than stigmasterol and the 7 times greater than cholesterol [38].

Cypermethrin is a pesticide with a chiral structure from the synthetic pyrethroids. When exposed to continuous and high doses, accumulates in the fat tissue and affects the central nervous system, reproductive organs, erythrocytes. Cypermethrin is usually determined by gas chromatography-mass spectrophotometry (GCMS). Prior to this application, facilitating extraction and eliminating the cleaning steps before analysis is of great importance for time and economy. Shaikh et al. prepared molecularly imprinted composite cryogel membranes for selective extraction prior to GC-MS applications. In this study, a and b-cypermethrin imprinted two different particulates were used to synthesized composite membranes. Deltamethrin and permethrin were used as competitive agents to determine the selectivity of the imprinted membranes and the imprinted membranes were determined to be highly selective for a and b cypermethrin. Cypermethrin solutions in $\mathrm{CH}_{2} \mathrm{Cl}_{2}$ were used at $1-100 \mu \mathrm{g} / \mathrm{mL}$ concentrations to determine the adsorption capacity of the prepared membranes. $\mathrm{pH}$ studies were performed between 1.0-9.0 to find the optimum $\mathrm{pH}$. Methanol was used for desorption agent and the final extract was analyzed by GC-MS. In order to validate the accuracy of the method, 3 repetitive ex- periments were carried out from the synthetic waste water with the addition of $a$ and $b$ cypermethrin and the calibration graph was drawn and the sensitivity of the method was determined by the slope. According to the experiments, it was possible to obtain a clean sample before the analysis with highly selective and reusable composite cryogel membranes [39].

One of the new methods used to purify and separate organic solvents is the organic solvent nanofiltration membranes. Light, radiation and plasma induced modification techniques are studied to increase the selectivity and stability of these materials which are generally used in the solvent treatment, pharmaceutical field and catalyst regeneration. Székely et al. synthesized organic solvent nanofiltration membranes in which the polybenzimidazole was first used as a functional monomer with the phase immersion molecular imprinting technique to increase selectivity. Polybenzimidazole was dissolved in N,N-dimethylacetamide and 2-aminopyrimidine was used as the template molecule. Three different membranes were synthesized in different percentages by weight. The samples were analyzed by HPLC. The effects of sample concentrations and applied pressures on molecular recognition were investigated using Sips and Freundlich isotherms. The surface area of the imprinted membranes was found to be $19 \%$ higher than the nonimprinted membranes by BET analysis [40].

Synephrine is an alkaloid obtained from the bitter orange (Citrus aurantium). It is generally used as a stimulant and concentration enhancer in herbal supplement products and as a metabolizing fat tissue in herbal slimming medication. Fan et al. synthesized synephrine imprinted membranes based on methacrylic acid and 2-hydroxy etacrylate (HEA) to purify synephrine. They have given flexibility to the membranes by using 1-butyl-3methylimidazolium bromide, as a porogen. In this study, 15 different porous membranes containing different amounts of crosslinker and monomer were prepared and compared. In the selectivity studies, octopamine and tyramine were used which have similar structures with synephrine. According to this, the synephrine selectivity of imprinted membranes was 2.68 times higher than octopamine and 2.57 times higher than tyramine. Chromatographic separation was monitored by high performance liquid chromatography (HPLC) [41].

The D- and L- amino acids have the same content with each other, and the only difference is that they are in 
mirror image. Eukaryotic organisms have L- amino acids while D- amino acids are found in bacterial proteins. Although this difference may seem insignificant, the Dand $L$ - amino acids have different biological and toxic effects. In particular, the presence of D- amino acids in the food industry refers to bacterial contamination. L- phenylalanine, one of the essential amino acids, which is used as a supplement in the food and beverage industry. It is also a genetic disorder, the phenylketonuria diagnosis reagent. Akgönüllü et al. have synthesized molecularly imprinted PHEMA based cryogel membranes for chiral separation of L-phenylalanine. The cryogels are prepared by the polymerization under the freezing point of the solvent. They are large and interconnected porous structures and can be synthesized in different forms. The functional monomer (N-methacryloyl-L-phenylalanine), monomer (HEMA), crosslinker (N-N-methylene-bisacrylamide), initiator/ activator (APS/TEMED) were used to synthesize at $-12^{\circ} \mathrm{C}$ between two glass plates. The chiral separation of Land $\mathrm{D}$ - phenylalanine was monitored using fast protein liquid chromatography [42].

Ractopamine is a $\beta 2$-agonist and is used as an additive in feed of livestock because it causes the growth of muscle tissue. When it is consumed, it is accumulated in animal tissues and transferred to people through food chain. The exposure of high amounts of ractopamine is harmful to human health, so ractopamine analysis in foods is great importance. Qui et al. were synthesized ractopamine imprinted nanotube membranes on anionic alumina oxide surface by atomic transfer radical polymerization. Methacrylic acid and EGDMA were used as functional monomer and crosslinker, respectively. Experiments were performed in different template/functional monomer ratios and the optimum ratio was $1 / 6$. The extraction process was performed with ractopamine and its antagonist, dopamine epinephrine, terbutaline, clenbuterol. Samples extracted with molecular imprinted nanotubes were analyzed by HPLC. The detection limits were within the range of $0.074-0.25 \mu \mathrm{g} / \mathrm{L}$ [43]. Asliyüce et al. prepared hepatitis B antibody imprinted composite cryogel membranes in two steps for use in the hepatitis B vaccine. Firstly, the pre-complex between the template molecule and the amino acid based functional monomer ( $\mathrm{N}$-methacryloyl L-tyrosine methyl ester) was formed and the monolithic column was synthesized by the bulk polymerization method using HEMA, crosslinker EGDMA and porous toluene together. The synthesized column was dried and crus- hed to obtaine hepatitis B imprinted particles. In the second step, these particles are embedded in pHEMA based cryogel membranes to increase the surface area of the large porous structure. The cartridges prepared by overlapping the membranes as sheets were used in adsorption experiments from human plasma with hepatitis B immunity and maximum adsorption capacity was found about $700 \mathrm{mlU} / \mathrm{g}$. The selectivity studies in which Hepatitis A and IgE were selected as competing agents showed that imprinted membranes were more selective about 5 and 9 times for hepatitis B antibody, respectively. The effective separation of hepatitis $B$ antibody from human plasma was demonstrated by fast protein liquid chromatography (FPLC) [44].

One of the most important difficulties encountered during sample analysis by mass spectroscopy is low analyte concentration. Li et al., used a combination of electrospray ionization and molecular imprinting technology to selective and simultaneously analyze samples containing low concentration analytes. Acrylic acid based imprinted polymers are crosslinked onto the polyvinylidene difluoride. After this step, the prepared membranes were used for direct ionization and mass spectroscopy analysis. In the mentioned study, different ionization methods such as nano spray and paper spray ionization were used to compare the method with the electrospray ionization and the method chosen accordingly was determined to be 10-50 times more sensitive than the other methods. In the study, methotrexate from blood, ciproftoxacin from milk, clenbuterol hydrochloride from urine, chlorpyrifes from soil analyzes were performed using multiple samples. Researchers have also shown that the use of molecular imprinting in many different areas [45].

\subsection{The Principle of Drug Delivery Systems}

A pharmaceutical compound, which achieves an optimal therapeutic effect in humans or animals, is administered by a process or method called drug delivery. There has been a rapid growth in drug delivery systems (DDS) over the last few decades. The drug delivery strategy of a drug plays a very important role on its effectiveness. Some drugs need to be administered at the optimum concentration (controlled release) to show maximum therapeutic effect, otherwise a higher or lower amount of certain drugs may produce side effects such as toxicity. The release of drugs at a controlled rate to the right target within the required time, their conversion to the 
harmless and non-toxic molecules in the body, the biocompatibility or biodegradability of the drugs are several important problems in DDS. Thus, ideal delivery means will ensure that the drug is released at the right place, at the correct dose and within the required time, and has no toxic effect on the host. Interdisciplinary approaches are constantly being used to minimize the problems. Polymer chemistry has been on the forefront of current controlled DSS, because of its multi-directional features and easyto-design architecture. Therefore, the majority of current controlled DDS are polymer-based.

Four types of DDS can be reported such as diffusion-controlled, swelling-controlled, erosion-controlled and stimulus-controlled [46]. The first, diffusion-based delivery systems developed for controlled release was based on the concentration gradient of the drug. Fick's diffusion laws often limit the release, resulting in non-linear Fickian release profiles. In swelling controlled systems, swelling increases polymer flexibility and creates larger pores and provides better drug mobility. As a result, the drug release profiles may be pseudo-linear for short periods, a combination of Fickian diffusion and polymer disentanglement and dissolution during the swelling. Erosion controlled systems have been developed by chemical or physical erosion of the polymer or material which are biodegradable, in order to control drug delivery. Actually, erosion is usually a combination of mass transport and chemical reaction, which includes polymer degradation, drug dissolution, micro environmental changes at $\mathrm{pH}$, porosity formation, diffusion in the polymer matrix and autocatalytic effects. Therapeutic drugs also can be released by a stimulus causing a physical or chemical change in the delivery system, which is called stimulus-controlled drug delivery. The release of the therapeutic agent is occurred by the change in the polymer matrix. $\mathrm{pH}$, physical changes in temperature, or chemical composition are used as common stimuli. The changes in ionic strength, temperature, electrical fields, $\mathrm{pH}$ and UV or visible light irradiation and the presence or absence of chemicals are used as stimuli. The imprinted hydrogels modulate (collapse and swell) to conform to the conditions under which the polymer will be used to release the therapeutic agent. It has also been reported that the drug release profiles of molecularly imprinted polymer-based DDS are not impressive compared to other controlled polymer systems; however, they act as an intelligent feedback-controlled DDS that senses the surrounding environment and triggers drug release in the overexpression of biomarkers in any disease state $[47,48]$.

\subsubsection{Biomimetic Molecularly Imprinted Polymers} as DDS

Synthetic networks, which can be designed to recognize and bind biologically important molecules, have a great importance and impact in many new technologies. These artificial materials may be used as unique systems or may be incorporated into existing drug delivery technologies, which may assist in the delivery of therapeutic agents or removal of biomolecules. Biomimetic networks, which can be used for controlled delivery of drugs, are prepared by creating a molecular structure based on biological interactions stabilized by a threedimensional structure between the building blocks of a biocompatible network and the desired specific ligand. This structure is also flexible enough to permit diffusional mass transport of the solvent and ligand into and out of the network. Functionality that is typically used in non-covalent systems is generally similar to those found in biological systems. The recognition of biomolecules in nature is the combination of multiple interactions between individual atoms and cumulative interactions between secondary structures. For example, the active regions of the enzymes consist of several amino acid residues bind the ligand molecules non-covalently. The activity of the region, however, depends on the stabilization of the three-dimensional structure by the interactions the residues within the structure of the secondary and tertiary regions [49].

Polymeric materials are accepted as a wonderful drug delivery device. The drugs are dispersed within the polymer matrix releasing the drug over a prolonged period of time or under certain physiological conditions. Hence, it is easier to handle various harmful effects caused by the narrow therapeutic window and the concentration below required levels. However, in these polymeric matrices, the release of an explosive that has potentially serious consequences for the patient has been widely found. Unfortunately, the burst release of the drug, which is a potentially serious problem for the patients, was frequently observed. Although better polymeric structures have been designed, other problems such as feedback-controlled release have limited their application fields $[50,51]$.

Alvarez-Lorenzo et. al. have also been detailed the mechanism and the applications of MIP-based intelligent DDS in the form of book chapters [52-55]. In general, molecularly imprinted polymers as a drug reservoir were cross-linked with a high degree to retain 
complementary cavities. However, densely crosslinked polymers are not preferred for drug delivery, especially when water-soluble monomers are used. MIPs have shown high stability and durability against hard conditions such as mechanical, thermal, acidic and basic conditions [56]. It is possible to store dried MIPS at ambient conditions for several years without losing its recognition features. Also, they have resistance to crushing and grinding. These features are advantageous, especially for sustained release of drugs in the human body. Unstable non-polymeric formulations can be affected easily from the acidic environmental of the gastrointestinal system leading to burst release. MIPs prepared by covalent or non-covalent approach can be used to obtain controlled release of drugs by increasing and decreasing residence time of drug in the polymer matrix. Especially, it can be useful to protect the body from the side effect of excess drug at a particular time. Besides, it is possible to use MIPs to release the more effective enantiomer selectively, when a particular enantiomer is administered to the patients [57]. Molecularly imprinted polymer, which delivers small pharmaceuticals, was used as DDS firstly. The synthesis of DDS has largely mimicked the synthesis of MIPs developed for analytical purposes. Although Vlatakis et. al. described a method firstly for creating selective recognition sites in synthetic polymers mimicking antibody combining sites [58], then several other groups have used this synthesis process for DDS [59]. Methacrylic acid (MAA) as the functional monomers was chosen because of its ionic interactions with amino groups and hydrogen bonds with polar functional groups on the imprinted molecule, and ethylene glycol dimethacrylate (EGDMA) was used as the crosslinker in the polymerization of MIPs. At last, MIP was acquired with excellent selectivity for the template drug molecule. Norell et al. synthesized first successful drug delivery system with a similar approach for sustained release of theophylline molecule, which is a pharmaceutical for the treatment for asthma, and also have a significant toxic effect with excess dosage [60]. The study showed that the interactions of the molecularly imprinted systems became less specific at higher drug loading concentrations, because the drug loading was attributed to partially nonspecific weak binding interactions. White et al. expanded upon molecularly imprinted soft contact lens technology to deliver a high-molecular weight hydroxypropyl methyIcellulose for 60 days [61]. In contrast to utilizing therapeutic agents as imprinting templates, researchers can imprint biomarkers that facilitate targeted drug release.
These systems use surface imprinting of whole proteins or epitopes to carry out the targeting of material, while encapsulating or adsorbing small-molecule drugs in the polymer network. Recently, the breast cancer xenografts actively targeted using an emulsion polymerization with epitope imprinting of the p32 receptor was achieved by Zhang and coworkers. Molecular imprinting improved the cellular uptake of the drug-containing nanogels and cytoplasmic delivery of the photosensitizer, methylene blue [62]. Likewise, Shen et. al. prepared bacteria-imprinted chitosan beads by emulsion polymerization. Surface-imprinted chitosan beads were used to recognize specific bacterial strains [63]. Çetin and Denizli have prepared 5-fluorouracil (5-FU) imprinted cryogel discs using a coordination complex between metal-chelate monomer $\mathrm{N}$-methacryloyl-L-histidine (MAH) and 5-FU with the assistance of $\mathrm{Cu}^{2+}$ ion [64]. The complex was copolymerized with 2-hydroxyethyl methacrylate to produce poly(hydroxyethyl methacrylate$\mathrm{N}$-methacryloyl-(L)-histidine methyl ester) cryogel discs. It was observed that the cumulative release of 5-FU decreased by the increasing cross-linker density, and 5-FU transport mechanism was found to be non-Fickian. In another study, Çetin et. al. prepared an implantable and degradable molecularly imprinted cryogel for $\mathrm{pH}$ responsive delivery of doxorubicin (DOX) [10]. The release rate of DOX from cryogel discs increased in more acidic conditions. Kinetic studies have shown that the general release behavior of molecularly imprinted cryogel discs was a combination of diffusion and erosion control. Öncel et. al. prepared an implantable mitomycin C imprinted poly(2-hydroxyethyl methacrylate-Nmethacryloyl-L-glutamic acid) membranes designed for the delivery of antineoplastic agent, mitomycin C [65]. In a previous work, Türkmen et. al. have already synthesized mitomycin C-imprinted magnetic poly(hydroxyethyl methacrylate)-based nanoparticles (MIMNs) using surfactant free emulsion polymerization for controlled delivery of mitomycin C [66]. Caka et. al. synthesized poly(HEMA-MAPA) membranes used for the controlled release of curcumin via UV-polymerization technique [67]. Curcumin is used as a folk remedy and a drug for some certain diseases and cancers. The time-depended release of curcumin was investigated and its slow release from the membrane has been demonstrated within 48h. More recently, single-walled carbon nanotubes (SWCNTs)-doping fenbufen imprinted polymer nanocomposite prepared with binary green porogen system to be used as a potential controlled-release device [68]. Bakhshpour et. al. synthesized by PHEMA based cryogel 
membranes using metal ion coordination interactions with $\mathrm{N}$-methacryloyl-(L)-histidine methyl ester (MAH) functional monomer and template molecule, mitomycin C [69]. Mitomycin C imprinted cryogel membranes prepared by radical suspension polymerization technique have a very high drug loading efficiency (70-80\%) and sustained drug release over hours. Moreover, Canfarotta et. al. achieved the specific recognition of a protein and selective delivery of a drug by the synthesis of molecularly imprinted polymer nanoparticles (nanoMIPs) loaded with doxorubicin and targeted toward a linear epitope of epidermal growth factor receptor [70].

In conclution, DDS began to extend from small pharmaceutical drugs to large biomolecules, such as proteins with the rapid development of material chemistry, which macro-scale evolved into micro- and nano-scale. MIPs having a potential approach for molecular recognition, electrochemical sensors, analytical sample enrichment, and chromatographic separation are still in the early stages of development as drug delivery carriers, but they are promising. Although, MIPs have led to difficulties about their biocompatibility and efficacy of drug release; MIP-based materials offer better drug loading and prolonged release over a longer period of time. Thus, MIPs are new alternatives as drug delivery vehicles.

\subsection{Biosensors}

Biosensors and chemical sensors have recently increased interest in the range of approaches and techniques applied. A sensor is a device that receives a stimulus and responds with an electrical signal [71,72]. Leland and C. Clark established the term "biosensor" using a biorecognition element (biological sensing element or bioreceptor) to detect diverse analytes in 1962 [73]. A Biosensor-based research in the world has increased with the studies in various fields such as food, biotechnology, medicine, and environment [74]. Biosensors detect devices that may be used to analysis and diagnoses analytes by converting a biological response to a signal. These devices include a biorecognition element (capturing element; enzyme, antibody, tissue, microorganism, cell receptor, and organelle). The specific interaction
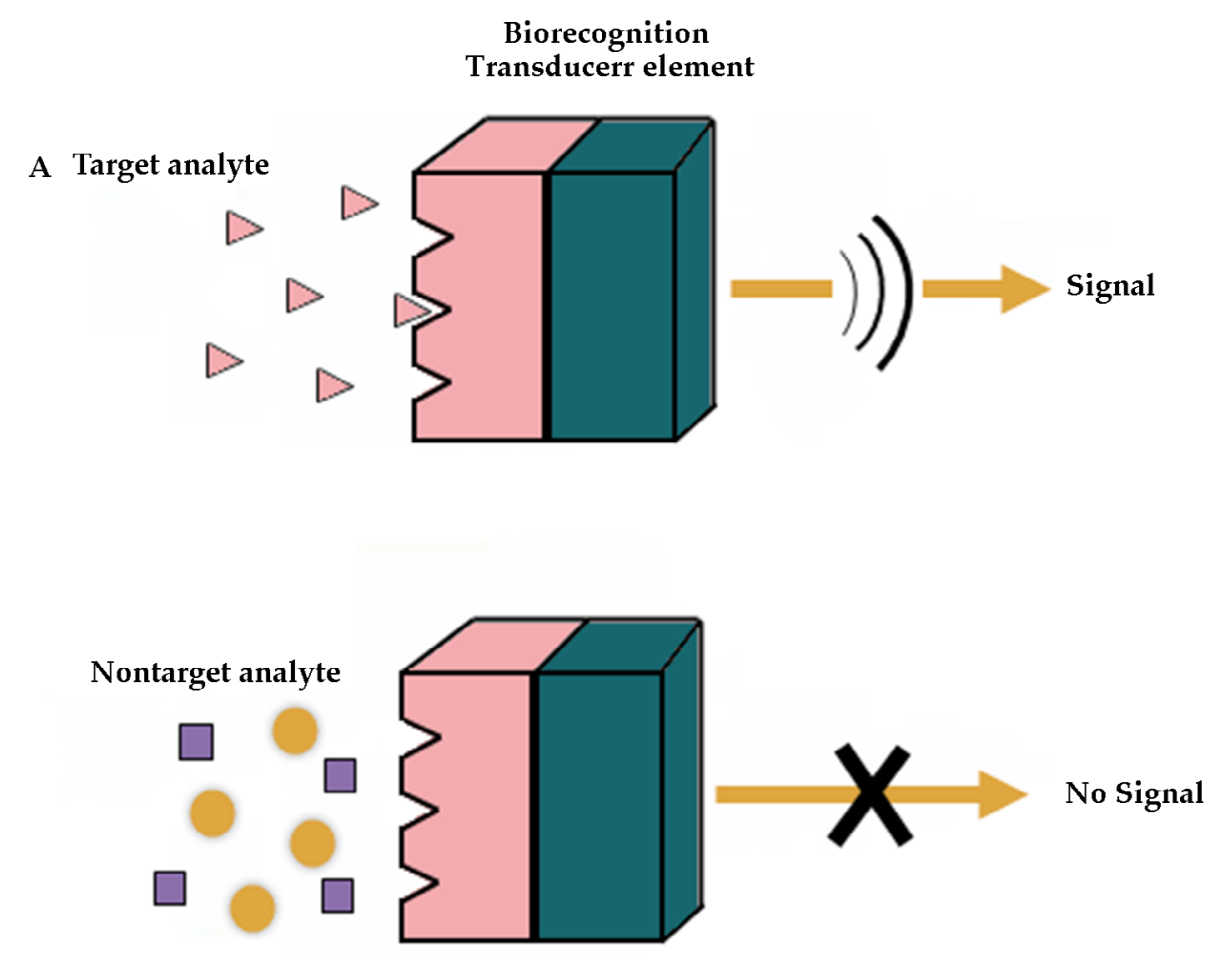

Figure 3. Schematic representation of the biosensor working model. 
between a target molecule and biorecognition element produces a physicochemical signal by a transducer. The physicochemical transducer then gives an analog electronic signal proportional to the concentration of an analyte. Biosensors are defined utilization various terminologies according to their activities, such as chemical resonant mirrors, biochips, immunosensors, biocomputers, glucometers, optrodes and canaries. The performance of a biosensor has several advantageous parameters such as specificity, sensitivity, reusability, size, large-scale production, quickness of diagnostic tests, and cost $[75,76]$.

Biosensors consist of two building blocks:

A) Bioreceptor (biorecognition element, which performs as a sensor)

B) Transducer (sensing element, which transmits a signal)

The biorecognition element can be enzymes, antigens, antibodies, living cells, tissues RNA, and DNA. The basic concept of a biosensor is summarized in Figure 3. At the time of determination, a physicochemical change take places on the sensing element surface and a signal that is directly measured or converted to another signal is obtained. These analyte-bioreceptor interactions are important because a signal is not transmitted if the specific analyte cannot bind to the biorecognition element [77].

\subsubsection{Bioreceptor}

The biorecognition elements or bioreceptor are the keys to specific interaction for biosensor techniques. A biorecognition element is a ligand species that use a biochemical reaction for recognition. They are responsible for binding the target analyte to the sensor for the analysis. Biorecognition elements can usually be classified into five different main categories. These categories include nucleic acids/DNA, enzymes, cellular structures/cells, antibody/antigen, bacteriophage and biomimetic. In biosensor applications widely used major classes of the biorecognition elements are antibodies, enzymes, and nucleic acid [74].

\subsubsection{Biomimetic receptor}

A bioreceptor which is designed and produced to mimic a biorecognition element (nucleic acids, antibody, enzyme or cell) is constantly called a biomimetic receptor. Compared to various methods such as synthetic membrane production and genetically modified molecules, the molecular imprinting technology has emerged as an attractive and widely accepted technique for the improved of synthetic specific recognition agents. Molecular imprinting is one of the techniques of producing synthetic specific recognition sites by forming a polymer around a molecule which can be used as a target. Molecularly imprinted polymers (MIPs) can be synthesized for any analyte molecule and are capable of binding target molecules with affinity and specificity equally with biorecognition elements. The same basic principle applies if a MIP is used as a biorecognition element instead of a biomolecule (Figure 4) [72].

\section{Immunosensor \\ Analyte binding \\ MIP sensor

\author{
Immobilised \\ antibodies
}
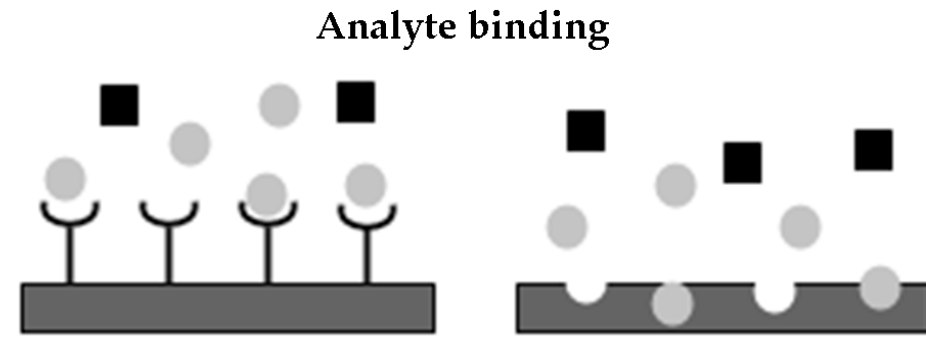 \\ Imprinted}

\section{Recognition element}

Figure 4. Schematic representation of a MIP-based biomimetic sensor compared to an immunosensor. 
Molecular imprinting technology is currently a versatile and cost-effective approach to the design of synthetic receptors. Due to their high affinities and selectivity that are similar to natural receptors, interest in MIPS has increased [78]. When MIPs are connected to a specific target in biomimetic-based sensors, the generation of an optical response (e.g., refractive index using surface plasmon resonance), mass-sensitive frequency change (e.g., mass change in quartz crystal sensors), or electrochemical signal (e.g., an impedance in electrochemical sensors It is based on. For this reason, the ease of adaptation of MIPs to practical applications in sensors has increased interest in applications of biomimetic based biosensors in different fields.

There are numerous technic barriers to the design of a selective and sensitive biosensors with the characteristics required for specific target molecule detection in a short time. Recent developments in biotechnology can provide the design of more effective biosensors.

There are a variety of sensing elements including mass, electric potential, viscosity, conductivity, impedance, electric current, temperature, intensity and phase of electromagnetic radiation. Various conditions have to provide to design a biosensor. Particular attention should be paid to the receptor recognition type and the immobilization method. The selection of receptors should be based on the ability to bind specific target materials and take into account their immobilization capacity [77].

Compared to conventional technologies such as spectroscopy and chromatography, biotechnology provides fast, low cost, on-site/in-situ and confidential detection methods for controlling biological dangers due to their small biosensor devices and their response properties [79].

\subsubsection{Immobilization}

To make a sensor, the biological or chemical components must be properly connected to the transducer. In this process, the morphology and activity of analyte (target molecule) should not be changed and this process is achieved by a method known as immobilization.

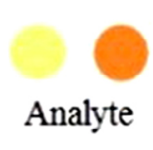

A

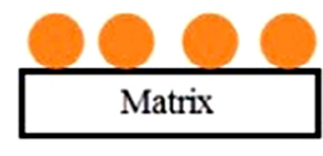

Adsorption

B

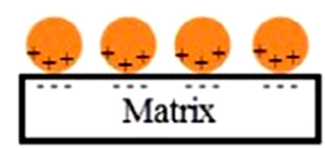

Ionic binding

C

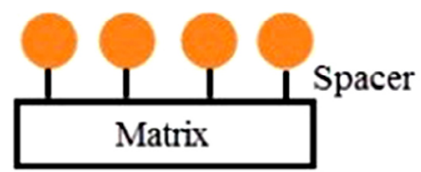

Covalent binding

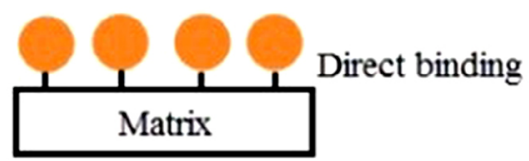

D
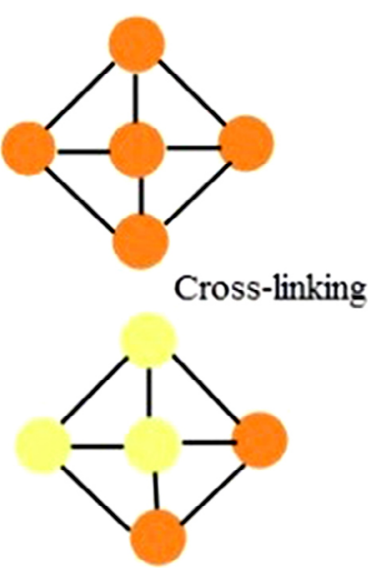

$\mathrm{E}$

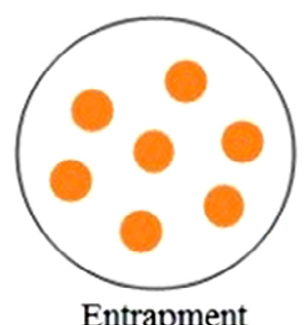

Figure 5. Immobilization models. 

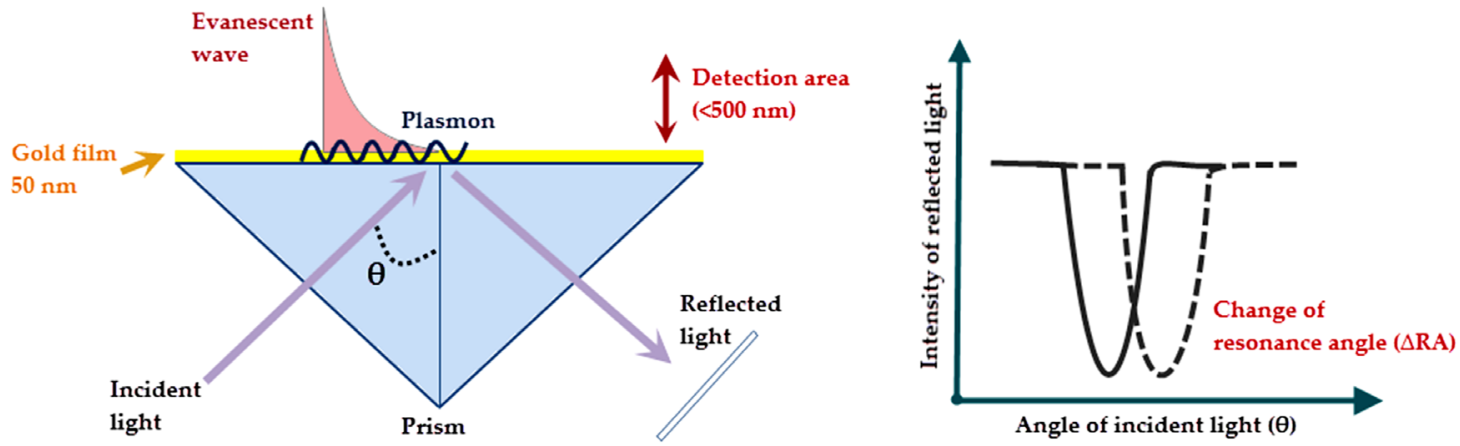

Figure 6. The basic principle of a surface plasmon resonance sensor. A gold-coated sensor chip is placed on a prism. The polarized light is sent from the sensor light source. The intensity of the reflected light is measured in the detector.

In order to immobilize a molecule, important elements are analyte, matrix, and binding procedure. Binding may occur through interactions ranging from physical adsorption to stable binding bonds. Various methods are used for immobilization. The immobilization methods based on different techniques are shown in the Figure $5[79-81]$.

\subsubsection{Types of biosensors}

Sensor types may be classified on the basis of detection elements or transducers. Recently, the most widely used electrochemical, optical and mass sensitive sensors are some of them.

\subsubsection{Optical biosensors}

The measured output signal of the optical-based sensors is the light emission that allows directly (label-free) detection. When target molecule binds to biorecognition element these sensor systems are able to detection minute changes. Optical biosensors are divided into several subclasses such as reflection, refraction, resonance, dispersion, phosphorescence, infrared absorption, Raman scattering, fluorescence, and chemiluminescence. Among these, surface plasmon resonance (SPR) based optical sensors are widely used because of their high sensitivity [79].

\subsection{Surface plasmon resonance (SPR) sensors}

Surface plasmon resonance (SPR) based sensors offer the advantage of rapid, label-free simultaneous monitoring of binding events due to refractive index changes near the sensor surface $[82,83]$. SPR biosensors can characterize the binding of target molecules to be determined on a sensor chip surface coated with a metal film (gold, $50 \mathrm{~nm}$ ) directly without any labeling. With SPR sensors it is possible to study the interactions of biological molecules such as proteins, oligonucleotides, and lipids, from macromolecules to small particles such as phages, viral particles and cells. As shown in Figure 6 , when the p-polarized light is reflected, the specific angle of incidence is reduced due to the resonance between the light golden film reflected in the glass and gold film interface and the amplitude-decreasing wave derived from the reflected light film. On the surface of the gold film, the specific angle, which changes by the refractive index $(\mathrm{RI})$ at the detection area $(<500 \mathrm{~nm})$, is called the resonance angle (RA) (Figure 6). Therefore, SPR sensors determine the RI changes from the change of RA in the determination region [84].

Surface plasmon resonance is a perfect method for monitoring changes in the refractive index in the immediate surround of the metal surface. When the refractive index changes, the minimum intensity observed angle will change as shown in Figure 7, where line A shows the graph of the reflected light intensity versus the incoming angle and $B$ is plot after the change in the refractive index. SPR can not only measure the difference between these two conditions, but also the change in time if the angle of resonance observed at the bottom changes. Figure 4 shows the shift of the so-called "sensorgram" of time. If this change is due to a biomolecular interaction, the kinetics of interaction can be examined in real time [84]. 


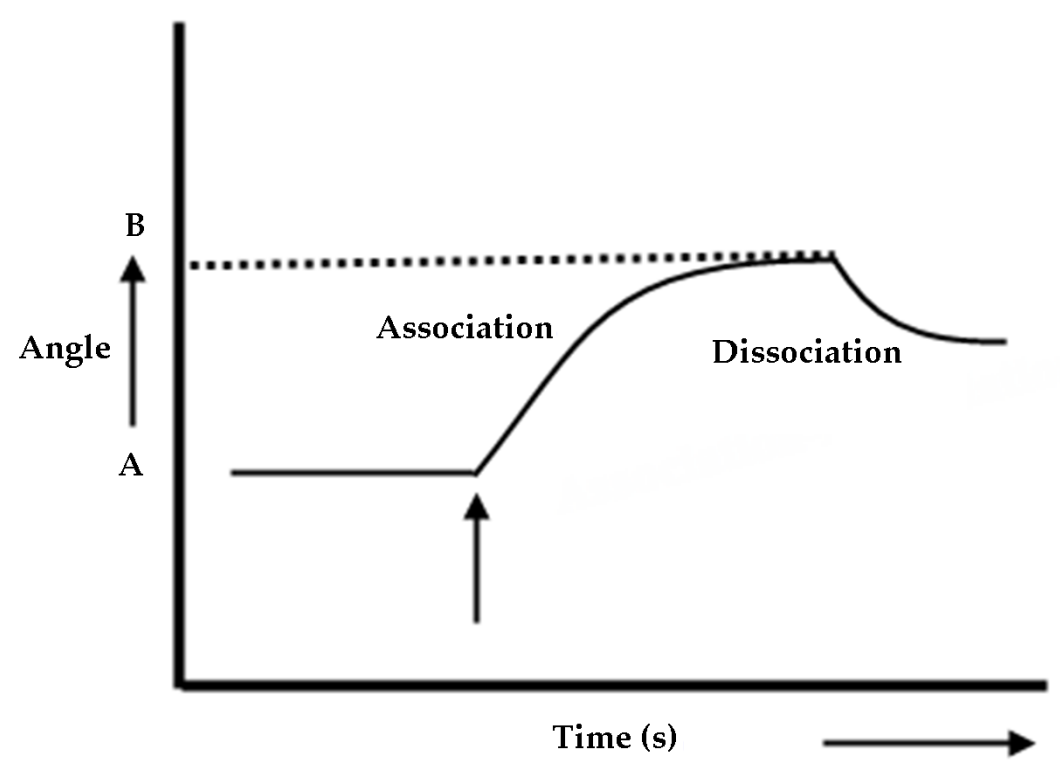

Figure 7. A sensorgram: principle of detection of analyt-ligand interactions by SPR sensor.

Table 1 summarizes the methods developed making use of SPR based sensors including MIP technique for the detection of target analytes in the various field of application. Several especially illustrating examples are discussed down there.

Pesticides applied to a broad range of composition, such as insecticides, herbicides, and fungicides. Use of pesticides exposure health dangers to humans, environment and non-target types due to their non-specific toxicological effects. Saylan et al., with surface plasmon resonance (SPR) sensors for fast, selective, sensitive and real-time detection of pesticides, including the most well-known triazine pesticides, atrazine (ATZ), cyanazine (SNZ) and simazine (SMZ). The biomimetic nanofilms onto the SPR gold surfaces are prepared, which consist of N-methacryloyl-I-phenylalanine methyl ester (MAPA) as a functional monomer,1-vinyl imidazole (VIM) as a co-monomer, and ethylene glycol dimethacrylate (EGD$\mathrm{MA}$ ) as a cross-linker. The real-time analysis on SPR sensor was performed a linearity range from 0.10 to 6.64 nM pesticide [82].

Melamine, a nitrogen-rich compound, was detected with surface plasmon resonance-based fiber optic sensor by using molecular imprinting method. The melamine imprinted polymer was coated over a metallic coating sensing probe. A molecular imprinted surface has cavities or specific binding sites like a porous structure with monomers for the specific target analyte. When a target molecule binds with the specific site of the molecularly imprinted layer then the molecule changes the interfacial structure of the surface and the refractive index. The change in the refractive index changes the resonance parameter. The detection of melamine was performed on linearity range from $10^{-7} \mathrm{M}$ to $10^{-1} \mathrm{M}$ [85]. 
Table 1. Surface plasmon resonance biomimetic sensors based on the use of MIPs.

\begin{tabular}{|c|c|c|c|c|c|c|}
\hline $\begin{array}{c}\text { Biomimetic } \\
\text { materials }\end{array}$ & Target & Sample & Linear range & LOD & $\begin{array}{l}\text { MIPs } \\
\text { preparation/ } \\
\text { assay time }\end{array}$ & Ref. \\
\hline \multicolumn{7}{|c|}{ Environmental analysis } \\
\hline $\begin{array}{l}\text { VIM-MAPA } \\
\text { nanofilm }\end{array}$ & Pesticide & in buffer & $0.10-6.64 \mathrm{nM}$ & $0.095 \mathrm{nM}$ & $3 \mathrm{~h}$ & [82] \\
\hline \multicolumn{7}{|l|}{ Food analysis } \\
\hline $\begin{array}{c}\text { Metallic } \\
\text { coating/MAA- } \\
\text { EGDMA }\end{array}$ & Melamine & in buffer & $10^{-7}-10^{-1} \mathrm{M}$ & $9.87 \times 10^{-9} \mathrm{M}$ & $24 \mathrm{~h}$ & [85] \\
\hline $\begin{array}{l}\text { MAA-EGDMA } \\
\text { polymeric film }\end{array}$ & Histamine & fish samples & $25-1000 \mu \mathrm{g} . \mathrm{L}^{-1}$ & $25 \mu \mathrm{g} \cdot \mathrm{L}^{-1}$ & $16 \mathrm{~h}$ & {$[86]$} \\
\hline \multicolumn{7}{|c|}{ Pharmaceutical and clinical analysis } \\
\hline $\begin{array}{c}\text { MAA:DVB } \\
\text { polymeric film }\end{array}$ & L-nicotine & $\begin{array}{l}\text { e-cigarettes or } \\
\text { spray medical } \\
\text { products }\end{array}$ & $0-10^{-3} \mathrm{M}$ & $10^{-8} \mathrm{M}$ & $16 \mathrm{~h}$ & [87] \\
\hline
\end{tabular}

Histamine $\left(\mathrm{C}_{5} \mathrm{H}_{9} \mathrm{~N}_{3}\right)$, an organic nitrogen compound, was first defined in 1910 by Laidlaw and Dale. Various methods have been improved for the detection of histamine. Histamine is a small molecule with a low molecular weight (111 Da). The detection of histamine molecularly imprinted polymers based SPR sensor was designed by Peng et al. In harsh environments can be used the biomimetic sensors with a biorecognition element. MIP films with high affinity and selectivity for histamine detection was prepared with MAA $(0.2 \mathrm{mmol})$ and EGDMA $(0.4 \mathrm{mmol})$ monomer phase and in the presence of the target molecule histamine $(0.1 \mathrm{mmol})$. The solution was coated on the gold surface of the SPR chip. Then, the template molecule removed with methanol/acetic acid $(9: 1, v / v)$ desorption agent. Also in this study, they examined the response of different monomer molar ratios. Histamine concentrations are performed within the concentration range of $25 \mu \mathrm{g} \mathrm{L}^{-1}$ to $1000 \mu \mathrm{g} \mathrm{L}^{-1}$ [86].

Cennamo et al., were designed the highly selective and sensitive SPR based biomimetic sensor for detection of L-nicotine. In this study, directly and selectivity detection of low molecular weight L-nicotine $\left(M_{w}=162.24 \mathrm{gmoL}\right.$ $\left.{ }^{1}\right)$ was successfully performed. The sensitivity strongly depended on the characteristics of tapered plastic optical fiber (POF) and the linearity range was from 0 to $10^{-3} \mathrm{M}$. The cost-effective optical-based chemical sensor system, based on a MIP surface and a tapered POF, was presented and directly performed for the selective detection of a low molecular weight L-nicotine [87].

\subsubsection{Electrochemical biosensors}

Electrochemical sensor is a device that converts the interaction of an analyte with a ligand on the surface of an electrode into a useful analytical signal. This technique DNA-binding drugs, glucose, and hybridized DNA are used for detection. In the electrochemical biosensor, measurable ions or electrons are produced or suppressed by different chemical reactions. Electrochemical sensors can be classified different analytical techniques; amperometric, potentiometric, or conductometric. These three electrochemical biosensors general summary is displayed in Table $2[74,84]$.

Table 3 summarizes the methods developed making use of electrochemical based sensors including MIP technique for the detection of target analytes in the various field of application. Several especially illustrating examples are discussed down there.

Prasad et al., a sensitive, selective, and rapid doubletemplate imprinted polymer nanofilm-modified pencil graphite electrode were designed for the real-time detection of phosphorus-containing amino acid-type herbicides (glyphosate and glufosinate) in soil and human serum samples. This sensor fabrication was binding of monomeric ( $\mathrm{N}$-methacryloyl-L-cysteine) molecules through S-Au bonds to gold nanoparticles immobilized sensor surface. Next, these molecules were synthesized on the polymer film sensor surface by free radical 
Table 2. Electrochemical sensing techniques.

\begin{tabular}{|c|c|c|c|}
\hline \multirow{2}{*}{ Characteristics } & \multicolumn{3}{|c|}{ Electrochemical-based sensing methodology } \\
\hline & Potentiometric & Amperometric & Conductometric \\
\hline Parameters & Voltage & Current & Conductance/resistance \\
\hline Applied Voltage & Ramp voltage & DC & $A C$ \\
\hline Sensitivity & & High & Low \\
\hline Dominant Equation & Nernst eqn. & Cottrell eqn. & Incremental resistance \\
\hline Fabrication & FET + enzyme oxide electrode & $\begin{array}{l}\text { FET + enzyme } \\
\text { (2 electrodes) }\end{array}$ & $\begin{array}{l}\text { Field effect transistor (FET) + } \\
\text { enzyme }\end{array}$ \\
\hline
\end{tabular}

polymerization in the presence of a crosslinker, initiator, and multiwalled carbon nanotubes as a pre-polymer mixture. In the real-time analysis, the linear ranges of glyphosate and glufosinate were 3.98-176.23 $\mathrm{ng} \mathrm{mL}^{-1}$ and $0.54-3.96 \mathrm{ng} \mathrm{mL}^{-1}$. The limit of detection as $0.35 \mathrm{ng}$ $\mathrm{mL}^{-1}$ for glyphosate and $0.19 \mathrm{ng} \mathrm{mL}^{-1}$ for glufosinate in aqueous samples [88].

$17 \beta$-estradiol (E2), a typical endocrine-disrupting chemical, increases the risk of ovarian and breast cancer in women and poses a serious threat to early puberty in children. Furthermore, it also influences sex characteristics, reproduction, infertility and regulation of female development. Han et al., magnetic glassy carbon electrode (MGCE) and magnetic molecularly imprinted polymers (MMIPs) based a novel magnetic molecularly imprinted sensing film (MMISF) was designed for the detection of estradiol (E2). This research MMIPs were synthesized by in situ polymerizations of glutathione (GSH)-functionalized gold ( $\mathrm{Au}$ )-coated $\mathrm{Fe}_{3} \mathrm{O}_{4}\left(\mathrm{Fe}_{3} \mathrm{O}_{4} @\right.$ AuGSH) nanocomposites and aniline. The linear range of the MMISF for E2 was 0.025-10.0 $\mathrm{mmol} \mathrm{L}^{-1}$ with the limit of detection of $2.76 \mathrm{nmol} \mathrm{L}^{-1}$ [89].

Levofloxacin (LEV) is one of the third generation of fluoroquinolones. Wang et al., a new method was designed for the structures of a highly sensitive levofloxacin (LEV) sensor based on molecularly imprinted polymer combining with graphene-Au nanoparticles (G-AuNPs). In this electrochemical sensor, G-AuNPs significantly supported the electrooxidation of LEV on electrode while molecularly imprinted polypyrrole of LEV served as the recognition element. The LEV concentration in the range from 1.0 to $100 \mu \mathrm{mol} . \mathrm{L}^{-1}$ and a detection limit of was $0.53 \mu \mathrm{mol} . \mathrm{L}^{-1}$ in under optimized conditions. The MIP/G-
AuNPs-based electrochemical sensor was beneficial for the detection of LEV with highly sensitive, selective and good reusability [90].

Kan et al., an effective and simple MIPs based electrochemical sensors was suggested and designed by electropolymerization of pyrrole in the presence of bovine hemoglobin $(\mathrm{BHb})$ as a target molecule in the aqueous solution. This sensor was characterized by electrochemical impedance spectroscopy and differential pulse voltammetry. The experimental results displayed that the MIPs based electrochemical sensor possessed fast rebinding dynamics and a perfect recognition capacity to target molecule $\mathrm{BHb}$ in under the optimized conditions [91].

Gholivand et al., designed of a high selectivity voltammetric sensor for metronidazole by using a molecularly imprinted technique as recognition element was introduced. A metronidazole selective MIP and a nonimprinted polymer were synthesized and then incorporated in the carbon paste electrodes (CPEs). The sensor was applied for metronidazole detection using cathodic stripping voltammetric method. The MIP-CP electrode showed very high recognition ability in comparison to NIP-CPE. In this research, two linearity ranges of $5.64 \times 10^{-5}$ to $2.63 \times 10^{-3} \mathrm{mgL}^{-1}$ and $2.63 \times 10^{-3}$ to $7.69 \times 10^{-2}$ $\mathrm{mgL}^{-1}$ were performed. The detection limit of the sensor was calculated as $3.59 \times 10^{-5} \mathrm{mgL}^{-1}$. This sensor has been shown to be used successfully for the detection of metronidazole in biological fluids [92]. 
Table 3. Electrochemical sensors based on the use of MIPs.

\begin{tabular}{|c|c|c|c|c|c|c|}
\hline $\begin{array}{l}\text { Biomimetic } \\
\text { materials }\end{array}$ & Target & Sample & Linear range & LOD & $\begin{array}{l}\text { MIPs } \\
\text { preparation/ } \\
\text { assay time }\end{array}$ & Ref. \\
\hline \multicolumn{7}{|c|}{ Environmental analysis } \\
\hline $\begin{array}{l}\text { Double-temp- } \\
\text { late imprinted } \\
\text { polymer modifi- } \\
\text { ed GNPs-PGE }\end{array}$ & $\begin{array}{l}\text { Glyphosate and } \\
\text { glufosinate }\end{array}$ & soil & $\begin{array}{c}3.98-176.23 \mathrm{ng} \text {. } \\
\mathrm{mL}^{-1} \text { and } 0.54- \\
3.96 \mathrm{ng} \cdot \mathrm{mL}^{-1}\end{array}$ & $\begin{array}{c}0.13 \text { and } 0.19 \\
\mathrm{ng} \cdot \mathrm{mL}^{-1}\end{array}$ & $3 \mathrm{~h}$ & [88] \\
\hline \multicolumn{7}{|l|}{ Food analysis } \\
\hline $\begin{array}{c}\mathrm{Fe}_{3} \mathrm{O}_{4} @ \mathrm{Au}- \\
\text { GSH magnetic } \\
\text { sensing film }\end{array}$ & $\begin{array}{c}\text { 17ß-estradiol } \\
\text { (E2) }\end{array}$ & in milk powder & $\begin{array}{c}0.025-10.0 \\
\mu \mathrm{mol} . \mathrm{L}^{-1}\end{array}$ & $2.76 \mu \mathrm{mol} . \mathrm{L}^{-1}$ & $24 \mathrm{~h}$ & [89] \\
\hline \multicolumn{7}{|c|}{ Pharmaceutical and clinical analysis } \\
\hline $\begin{array}{l}\text { MIP/G-Au } \\
\text { modified } \\
\text { electrode }\end{array}$ & $\begin{array}{l}\text { Levofloxacin } \\
\text { (LEV) }\end{array}$ & in buffer & $1.0-100 \mu \mathrm{mol} . \mathrm{L}^{-1}$ & $0.53 \mu \mathrm{mol} . \mathrm{L}^{-1}$ & $5 \mathrm{~h}$ & [90] \\
\hline $\begin{array}{l}\text { MIPs modified } \\
\text { Au electrode } \\
\text { (MIPs/AuE) }\end{array}$ & $\begin{array}{c}\text { Bovine } \\
\text { hemoglobin } \\
\text { (BHb) }\end{array}$ & in buffer & $1.0 \times 10^{-5} \mathrm{~mol}^{\mathrm{L}^{-1}}$ & $1.0 \times 10^{-9} \mathrm{~mol}^{-\mathrm{L}^{-1}}$ & $2 \mathrm{~h}$ & [91] \\
\hline $\begin{array}{l}\text { Metronidazole } \\
\text { modified CPE }\end{array}$ & Metronidazole & biological fluids & $\begin{array}{c}5.64 \times 10^{-5}- \\
7.69 \times 10^{-2} \mathrm{mg}^{-1} \mathrm{~L}^{-1}\end{array}$ & $3.59 \times 10^{-5} \mathrm{mgL}^{-1}$ & $24 \mathrm{~h}$ & [92] \\
\hline
\end{tabular}

\subsubsection{Mass-sensitive biosensors}

Mass-sensitive biosensors, also known as piezoelectric biosensors, use piezoelectric crystals that are very sensitive and detect minor changes in mass [79]. The basis of this sensor is based on the vibration of the piezoelectric crystals at a certain frequency when an alternating electric current with a fixed frequency is applied. This frequency depends on the crystal mass. Chemical interactions affect the frequency of oscillations measured as an output signal [74]. Two main mass sensitive biosensors are i) bulk wave devices and ii) surface acoustic wave devices.

Table 4 summarizes the methods developed making use of quartz crystal microbalance (QCM) based sensors including MIP technique for the detection of target analytes in the various field of application. Several especially illustrating examples are discussed down there.

Yang et al., a high selectivity and sensitivity QCM sensor were developed for the detection of $\mathrm{Cu}(\mathrm{II})$ ions. The modification of $\mathrm{CU}$ (II) ion-imprinted polymer (CU(II)-IIP) film was coated onto a quartz crystal. The detection of heavy metal ions in living systems is one of the major issues because of their damage to the environment and human health. The synthesis procedure of $\mathrm{Cu}$ (II)-IIP film at the surface of quartz crystal could be described as follows, the mixed solution containing MAA $(0.035$ mmol) as a monomer, TMPTM $(0.05 \mathrm{mmol})$ as crosslinker and in the presence of target molecule $\mathrm{Cu}(\mathrm{II})$ ions (0.008 mmol). The practical analysis of the MIP-QCM sensor was performed broad linear range (0.001-50 $\mu \mathrm{M})$ and lower detection limit $\left(8 \times 10^{-4} \mu \mathrm{M}\right)$ confirms the applicability of $\mathrm{Cu}(\mathrm{II})$ detection in wastewater [93].

Formaldehyde is a pungent gas and is considered to be one of the main toxic closed pollutants; it is broadly used as an additive for preventing food spoilage, enhancing the flavor and brightening the color. Hussain et al reported a QCM sensor for detection formaldehyde vapors in air streams. MIP-based QCM sensor a copolymer thin film consisting of styrene, methacrylic acid, and ethylene glycol dimethacrylate provided a detection limit of 500 ppb formaldehyde in dry air [94].

Bisphenol A (BPA), which are broadly employed in diverse consumables and crops, has been generally used as a monomer in fabricating polycarbonate epoxy resins and plastics. It is claimed that it can be leached from plastic products such as food packaging materials and acts as an endocrine disrupting chemical. In this study 
Matsumoto et al. prepared bisphenol A (BPA) imprinted polypeptide gel layers based on cyclodextrin modified poly(L-lysine) (CD-PLL) on QCM sensor chips [95].

Clenbuterol (CLB) is a beta 2 adrenergic drug in the clinical medicine. It is a growth enhancer that used illegally in animal production. For the rapid and powerful determination of both parent clenbuterol (CLB) and its metabolites in swine urine samples, based on molecularly imprinted polymers QCM sensor for CLB detection was developed. In the polymer procedure, clenbuterol and the structural analogs of its metabolites, 4-hydroxymandelic acid (HMA) and 4-Aminohippuric acid (AHA) were chosen as target molecules. Feng et al., reached a limit of detection $\left(3.0 \mathrm{ngmL}^{-1}\right.$ ) lower than the Codex Alimentarius Commission regulations (residue limit 10.0 $\left.\mu \mathrm{LL}^{-1}\right)[96]$.

Synthetic cannabinoids (SCs) are chemical compounds the main active component of cannabis which mimics the effect of $\Delta-9$-tetrahydrocannabinol ( $\Delta 9$-THC). They bind to cannabinoid receptors in the brain and were essentially developed as therapeutic agents in the treatment of pain but when smoked produce marijuana-like effects. Battal et al., designed a sensitive quartz crystal microbalance (QCM) biomimetic sensor for detection of synthetic cannabinoids. In this research SCs-imprinted (MIP) and non-imprinted (NIP) nanoparticles were synthesized. Results displayed that the SCs-imprinted
QCM sensors exhibited high sensitivity and selectivity in a wide range of synthetic cannabinoid linearity (0.0005-1.0 $\mathrm{ngmL}^{-1}$ ) in synthetic urine solutions and both aqueous [97].

This section provides utility insights into electrochemical, surface plasmon resonance, and quartz crystal microbalance sensors based on the use of molecular imprinting method. Especially, the chosen contributions describe the development of SPR, electrochemical and QCM sensor to detection different analytes of concern in the different fields; environmental (pesticide, $\mathrm{Cu}(\mathrm{II})$, formaldehyde, glyphosate and glufosinate), food (E2, BPA, melamine and histamine) and clinical and pharmaceutical (SCS, CLB, L-nicotine, LEV, BHb, and metronidazole). MIP have been fabricated using a thin film, magnetic particles $\mathrm{Fe}_{3} \mathrm{O}_{4}$-NPs, Au nanoparticles, ion-imprinted polymer, and imprinted-nanoparticles. The use and implementation of new sensing projects based on new biomimetic MIPs are expected to be widely developed in the future, taking into account the excellent expectations of high sensitivity, selectivity, and convenience in the development of new nanomaterials offered by MIPbased SPR, electrochemical and QCM sensors.

\subsection{Biomimetic polymeric brushes}

The affinity chromatography technique is widely used in chemical purification, metal removal, sensor applications, and many other studies. In affinity chromatog-

Table 4. Quartz crystal microbalance sensors based on the use of MIPs.

\begin{tabular}{|c|c|c|c|c|c|c|}
\hline $\begin{array}{l}\text { Biomimetic } \\
\text { materials }\end{array}$ & Target & Sample & Linear range & LOD & $\begin{array}{l}\text { MIPs } \\
\text { preparation/ } \\
\text { assay time }\end{array}$ & Ref \\
\hline \multicolumn{7}{|c|}{ Environmental analysis } \\
\hline $\begin{array}{l}\text { Cu(II) ion-imp- } \\
\text { rinted polymer }\end{array}$ & $\mathrm{Cu}(\mathrm{II})$ & wastewater & $0.001-50 \mu \mathrm{M}$ & $8 \times 10^{-4} \mu \mathrm{M}$ & $24 \mathrm{~h}$ & {$[93]$} \\
\hline $\begin{array}{l}\text { MAA-EGDMA } \\
\text { thin film }\end{array}$ & Formaldehyde & dry air & 1-100 ppm & $500 \mathrm{ppb}$ & $80 \mathrm{~min}$ & {$[94]$} \\
\hline \multicolumn{7}{|l|}{ Food analysis } \\
\hline $\begin{array}{l}\text { cyclodextrin } \\
\text { modified poly(L- } \\
\text { lysine) (CD-PLL) }\end{array}$ & $\begin{array}{c}\text { Bisphenol A } \\
\text { (BPA) }\end{array}$ & $\begin{array}{l}\text { aqueous } \\
\text { solutions }\end{array}$ & $0-400 \mu \mathrm{M}$ & $24.499 \mu \mathrm{M}$ & $24 \mathrm{~h}$ & {$[95]$} \\
\hline \multicolumn{7}{|c|}{ Pharmaceutical and clinical analysis } \\
\hline $\begin{array}{c}\text { HMA-AHA } \\
\text { thin MIP film }\end{array}$ & $\begin{array}{l}\text { Clenbuterol } \\
\text { (CLB) }\end{array}$ & urine & $\begin{array}{c}1 \times 10^{-1}-1 \times 10^{-5} \\
\mathrm{mM}\end{array}$ & $3.0 \mathrm{ng} \cdot \mathrm{mL}^{-1}$ & $12 \mathrm{~h}$ & {$[96]$} \\
\hline $\begin{array}{l}\text { SCs-imprinted } \\
\text { nanoparticles }\end{array}$ & $\begin{array}{c}\text { Synthetic } \\
\text { cannabinoids } \\
\text { (SCs) }\end{array}$ & urine & $\begin{array}{c}0.0005-1.0 \mathrm{ng} / \\
\mathrm{mL}\end{array}$ & $0.3 \mathrm{pg} / \mathrm{mL}$ & $24 \mathrm{~h}$ & {$[97]$} \\
\hline
\end{tabular}


raphy often, natural ligands such as antibodies, antigens, enzymes, coenzymes, inhibitors enzyme substrates and hormones, inhibitors, effectors, coenzymes, nucleic acids, and sugars can be used. However, there are some critical deficiencies of natural ligands. Natural affinity ligands are quite expensive, immunogenic, and also not resistant to harsh working conditions and are likely to cause leakage in the environment of purification or removal. Also, natural affinity ligands -quite large molecules- are quite low the molecular imprinting efficiency. Because of this advantage scientists study about new polymeric support for the application. The new support name is biomimetic support (synthetic) materials. There are many different biomimetic ligands type which are triazine dyes, metal ions, hydrophobic or hydrophilic column and polymeric brushes. Biomimetic ligands have significant advantages such as being cheap, chemically resistant, easy to function and being revised for different chemical techniques. One of the best known biomimetic ligands are polymeric brushes can be used purification and separation processes.

Polymeric brushes can be synthesized by free radical, ring-opening metathesis polymerization, atom transfer free radical polymerization, reversible addition-fragmentation transfer polymerization, anionic polymerization techniques. With all of these methods, polymerization can be achieved with the appropriate monomer and initiator complex on the flat surfaces or the particle surface. In this section, the synthesis of polymeric brushes will not be explained, and only molecular imprinting examples of polymeric brushes will be given. Polymeric brushes first attracted the attention of scientists in the early 1950s. After that, theoretical studies have been carried out that polymeric brushes can be used for treatment purposes. In the first pioneering studies, the thin film surface of the polymeric brushes includes the work done. After many studies, especially in the 1990s, many applications of polymeric brushes have emerged. Nowadays, polymeric brushes are used in the area of the thin film surface, metal removal by binding to micro and nanoparticle surfaces, purification of the antibody, purification of DNA [98]. Why scientist use the polymeric brush? Polymeric brushes have advantages such as interfacial localization of terminal groups, diffusion control, regulation of steric repulsive forces, control of phase-segregation in response to external stimuli, wetting control, control of protein and cell adsorption, adsorption of molecules, lubrication, and flocculation control [98].
The molecular imprinting-based applications of polymeric brushes are entirely new. This section presents these examples of biomimetic polymeric brushes.

RAFT polymerization has proven to be one of the most potent controlled methods of living are radical polymerization (CRP) techniques. Pank et al. synthesized polymeric brushes using a reversible addition fragmentation chain transfer technique. For this purpose, waterbased and stimuli-responsive $\mathrm{N}$-isopropylacrylamide were synthesized from the spheres and synthesized phenoxyacetic acid due to the structural similarity of 2,4-dichlorophenoxyacetic acid from the aqueous medium. Also, the binding properties of the ungrafted and grafted MIPs/NIPs in both methanol/water and pure water solutions were investigated [99].

Ma et al. used nanosorbents to remove drug contaminants from wastewater. They prepared hydrophilic magnetic surface molecularly imprinted core-shell nanorod (HMMINs) brushes by applying a two-step surface-initiated atom transfer radical polymerization in a green alcohol/water solvent mixture with magnetic halloysite nanotubes (HNTs, a hollow tubular structured natural clay mineral) used as nano-cores. The core-shell structure is an ultra-thin imprinted film (12 $\mathrm{nm}$ ) and hydrophilic polymer brushes (2-4 nm), where magnetic nanoparticles (11 nm) were uniformly dispersed onto the surface of halloysite nanotubes. Surface grafting of the hydrophilic polymer brushes enhanced the adsorption selectivity with an adsorption capacity of 37.64-1.36 mmol g-1 and the kinetics (within $45 \mathrm{~min}$ ) towards a typical antibiotic drug sulfamethazine (SMZ) from pure water [100]. Dai et al. synthesized surface imprinted core-shell nanorod with ultrathin water-compatible polymer brushes for specific recognition and adsorption of sulfamethazine in a water medium. They used "living" polymerization technique, with magnetic attapulgite (MATP) as a core, and it was applicable in the enhanced selective removal of sulfamethazine residue from pure water environments [101].

In another study, Dai et al. studied the chemical molecule sulfamethazine, which is essential for monitoring and removal in surrounding waters. Sulfamethazine is increasing the public concern on the potential human health risks due to serious side effects such as allergies, carcinogenesis, and possible development of antibiotic resistance. Brushes removed Sulfamethazine hydrop- 
hilic poly (2-hydroxyethyl methacrylate) (PHEMA). Sulfamethazine removal was studied in the batch. During the study, adsorption isotherms were investigated and ungrafted imprinted materials were fitted [102].

Yang et al. synthesized molecularly imprinted hydrophilic quantum dots and used it to purify biological samples. Quantum-dot has unique properties such as broad excitation spectra, narrow and tunable emission, high luminescence efficiency, and strong resistance to photobleaching. In this study, the optosensor system for tetracycline (Tc, a broad-spectrum antibiotic) determination was developed. In the first phase of the study, QD polymer $\mathrm{SiO}_{2}$ composite microspheres were synthesized, and in the second step Tc-imprinted polymer and poly (glyceryl mono methacrylate) brush was synthesized by surface-initiated atom transfer radical polymerizations. In biological samples, Tc was reduced to $0.14 \mu \mathrm{M}$ and no false positive results were not found. Besides, it was possible to remove Tc from the biological medium directly, precisely, selectively and in a yield of $95 \%-105 \%$ by the MIP-based chemosensor prepared. In these measurements, it was observed that Tc did not interfere with other drugs [103]. Niu et al. in the same group suggested a different method for the efficient determination of Tc. In this method, a selective determination of a fluorescent hydrophilic polymer synthesized Tc as described above was carried out. This study limit was reduced to $0.26 \mu \mathrm{M}$ and was higher than the previous study. Similarly, a poly(2-hydroxyethyl methacrylate) (PHEMA) brush was used in a similar manner using a reversible addition-fragmentation chain transfer (RAFT) polymerization technique [104].

In the work of Prasad and Kumar, MIP nanoarrays of $\mathrm{N}$-acryloyl-2-mercapto benzamide are synthesized on a silver electrode for uracil and 5-fluorouracil detection. The procedure involved electrochemical etching of silver-wire to develop nanopores on its tip. In these nanopores, a prepolymer mixture with a template(s) was filled-in via spin coating and subjected to free radical thermal polymerization. Uracil (Ura) which is from the group of pyrimidines is involved in the biosynthesis of numerous enzymes necessary for cell functions through bonding with riboses and phosphates. The Ura derivative, 5-fluorouracil (5-FU), which has been reported as anti-tumor and anti-viral agents. Besides, overdoses of Ura and its derivatives produce toxic metabolite accumulation that causes neurotoxicity, inducing morbidity and mortality in humans. In the study, a detec- tion sensitivity as low as $0.50 \mathrm{ngmL}^{-1}$ for Ura and 0.33 ngmL $^{-1}$ for $5-F U$ is reported. The "surface imprinting" with nanoarrays on a silver substrate has been found to be advantageous to render a larger surface area with vertically aligned nanopores for uninterrupted masstransport and electron-transfer with high kinetics. The proposed nanoscale electrochemical sensor was also validated with the complex matrices of blood plasma and pharmaceutics which assured reliable results [105]. In another study, Oliveira et al. used RAFT precipitation polymerization for the molecular imprinting of 5-FU followed by grafting of polymer functional brushes in the particles surface. Mathematical modeling of the RAFT copolymerization of vinyl/divinyl monomers was used to describe the crosslinking process involved in the molecular imprinting step. The assessment of polymer reaction engineering tools to aid the design of synthesis conditions leading to tailored MIPs with responsive features was a critical goal of this research [106]. Along with the modeling study, the group synthesized and evaluated molecularly imprinted particles with surface grafted functional polymer brushes aiming to choose either methacrylic acid (MAA) or 2-hydroxyethyl methacrylate (HEMA) as functional monomers. The MAA imprinting system with PMAA grafted functional brushes shows the highest improvement in 5-FU release triggered by a $\mathrm{pH}$ change from 2 to 10 . The results showed the combined benefits of molecularly imprinted particles with surface grafted functional polymer brushes concerning molecular recognition and stimulated 5-FU release [107].

Patel et al. prepared uric acid imprinted polymeric brushes with an electrochemical sensor and selectively used in the determination of uric acid. It is essential to determine the urea determination in the hyper-uremic patient plasma and urine and present severe data for the course of the disease. The poly (melamine-co-chloranil) imprinted polymeric brush was prepared and used electrochemically in the determination of uric acid. Uric acid was selectively determined without causing any interference from aqueous media, urine and blood serum [108].

Despite most of produced MIPs can successfully achieve specific recognition in organic solvent-based media, they often show poor recognition ability for the target in aqueous environments because the presence of polar solvent can disturb the hydrogen bond formed between the template and functional monomer. Xua et 
al. tried to increase recognition ability for the target in aqueous environments with double water compatible molecularly imprinted polymers (DWC-MIPs) with water compatible core, and hydrophilic polymer brushes were prepared by reversible addition-fragmentation chain transfer precipitate polymerization (RAFTPP) and applied as solid-phase extraction (SPE) sorbent for selective preconcentration and specific recognition of triazines in water samples [109].

Folic acid is an essential vitamin and can cause serious health problems. Since it cannot be produced in the human body, it should be supplied through foods. Yang et al. used molecularly imprinted nanoparticles for the determination of folic acid from real samples. In this study, CdTe quantum points were synthesized by RAFT polymerization precipitation method. Grafted hydrophilic poly(glyceryl mono methacrylate) brushes incorporated into selectivity. They directly and selectively optosense folic acid undiluted bovine and porcine serums, with its limit of detection being $0.025 \mu \mathrm{M}$ [110].

Brucine, known as an alkaloid, exists mainly in the seeds of strychnos. Itisoftenusedasanti-inflammatory and analgesic drug to relieve arthritic and traumatic pains because of its effect on stimulating the central nervous system. Zhao et al. synthesized brucine imprinted nanotubes and modify with hydrophilic poly(glycerol mono methacrylate) brushes were used to increase water compatibility. The synthesized molecular pressurized material provides the selective recognition of the brush from the aqueous medium. The sensor can be used successfully for the determination of brucine in test samples [111].

\section{Conclusion and Perspective}

Scientists are often inspired by the nature. Thus, mimicking the nature to examine and solve the human problems in models, systems and processes has certainly been an important driving force with regards to biomedical and therapeutic applications since it gives possibility to proceed much faster than trial and error method. "Biomimetics" concept attract the attention of scientists to produce better drugs to interact specifically with the intended biomolecule, produce artificial organs, develop better sensors for the specific analytes, find better counterparts for the separation and purification processes etc.

Biomimetic surface design with improved adhesion and wetting properties with suitable thickness would perhaps reach better conditions with the advances in nanotechnology and evolution of surface patterning procedures. Better understanding of cell behavior in artificial environments will open the way to design efficient artificial tissues and organs and also be used in the tissue-on-chip platforms to constitute powerful drugs and biological research. Biomimetic-recognition capability for the interested molecules by using natural counterparts gives possibility to identify and separate them fast, simple and specific with high throughput. Molecular imprinting technology made enormous impact on various applications like separation and sensing and it seems it will be continued with the improvements in the identification and information of molecular properties of biologically important substances.

In summary with the development of related multidisciplinary technologies like natural sciences, engineering, computational and material sciences, biomechanics, neurosciences, robotics etc. biomimetic technology and applications expected to approach natures unique ability of using minimum resources to produce maximum benefit.

\section{References}

1. B. Chen, S. Piletsky, A.P.F. Turner, Molecular Recognition: Design of "Keys," Comb, Chem. High Throughput Screen., 5 (2002) 409-427.

2. H. Yavuz, K. Çetin, S. Akgönüllü, D. Battal, A. Denizli, Therapeutic protein and drug imprinted nanostructures as controlled delivery tools, in: Alexandru Mihai Grumezescu (Ed.), Des. Dev. New Nanocarriers, William Andrew Publishing, (2018) 439-473.

3. M. Cieplak, W. Kutner, Artificial Biosensors: How Can Molecular Imprinting Mimic Biorecognition?, Trends Biotechnol., 34 (2016) 922-941.

4. F.H. Dickey, Specific Adsorption, J. Phys. Chem., 59 (1955) 695-707.

5. G. Wulff, R. Grobe-Einsler, W. Vesper, A. Sarhan, Enzymeanalogue built polymers, 5 . On the specificity distribution of chiral cavities prepared in synthetic polymers, Die Makromol. Chemie., 178 (1977) 2817-2825.

6. R. Arshady, K. Mosbach, Synthesis of substrate-selective polymers by host-guest polymerization, Die Macromol. Chemie., 182 (1981) 687-692.

7. W. Shi, S.Q. Zhang, K.B. Li, W.P. Jia, D.M. Han, Integration of mixed-mode chromatography and molecular imprinting technology for double recognition and selective separation of proteins, Sep. Purif. Technol., 202 (2018) 165-173.

8. A.M. Shrivastav, S.P. Usha, B.D. Gupta, Fiber optic profenofos sensor based on surface plasmon resonance technique and molecular imprinting, Biosens. Bioelectron., 79 (2016) 150157. 
9. Y. Saylan, S. Akgönüllü, H. Yavuz, S. Ünal, A. Denizli, Molecularly imprinted polymer based sensors for medical applications. Sensors, 19, (2019) 1279.

10. K. Çetin, H. Alkan, N. Bereli, A. Denizli, Molecularly imprinted cryogel as a $\mathrm{pH}$-responsive delivery system for doxorubicin J. Macromol. Sci. Part A Pure Appl. Chem., 54 (2017) 502508.

11. L. Cenci, R. Tatti, R. Tognato, E. Ambrosi, C. Piotto, A.M. Bossi, Synthesis and characterization of peptide-imprinted nanogels of controllable size and affinity, Eur. Polym. J., 109 (2018) 453-459.

12. Z. He, S. Zang, Y. Liu, Y. He, H. Lei, A multi-walled carbon nanotubes-poly(L-lysine) modified enantioselective immunosensor for ofloxacin by using multi-enzyme-labeled gold nano flower as signal enhancer, Biosens. Bioelectron. 73 (2015) 85-92.

13. J.B. Carbajo, A.L. Petre, R. Rosal, S. Herrera, P. Letón, E. García-Calvo, A.R. Fernández-Alb, J.A. PerdigónMelóna, Continuous ozonation treatment of ofloxacin: Transformation products, water matrix effect and aquatic toxicity, J. Hazard. Mater., 292 (2015) 34-43.

14. P. Qu, J. Lei, L. Zhang, R. Ouyang, H. Ju, Molecularly imprinted magnetic nanoparticles as tunable stationary phase located in microfluidic channel for enantioseparation, J. Chromatogr. A., 1217 (2010) 6115-6121.

15. H. Peng, M. Luo, H. Xiong, N. Yu, F. Ning, J. Fan, Z. Zeng, J. $\mathrm{Li}, \mathrm{L}$. Chen, Preparation of photonic-magnetic responsive molecularly imprinted microspheres and their application to fast and selective extraction of $17 \beta$-estradiol, J. Chromatogr. A., 1442 (2016) 1-11.

16. R. Gutierrez-Climente, A. Gomez-Caballero, A. Guerreiro, D. Garcia-Mutio, N. Unceta, M.A. Goicolea, R.J. Barrio, Molecularly imprinted nanoparticles grafted to porous silica as chiral selectors in liquid chromatography, J. Chromatogr. A., 1508 (2017) 53-64.

17. E. Bayram, E. Yılmaz, L. Uzun, R. Say, A. Denizli,. Multiclonal plastic antibodies for selective aflatoxin extraction from food samples, Food Chem., 221 (2017) 829-837.

18. Y. Tang, J. Gao, X. Liu, X. Gao, T. Ma, X. Lu, J. Li, Ultrasensitive detection of clenbuterol by a covalent imprinted polymer as a biomimetic antibody, Food Chem., 228 (2017) 62-69.

19. Y. Wu, J. Lu, X. Lin, J. Gao, L. Chen, J. Cui, P. Lv, X. Liu, M. Meng, Y. Yan, Bioinspired Synthesis of Janus NanocompositeIncorporated Molecularly Imprinted Membranes for Selective Adsorption and Separation Applications, ACS Sustain. Chem. Eng., 6 (2018) 9104-9112.

20. Q.Y. Ang, S.C. Low,. Morphology and kinetic modeling of molecularly imprinted organosilanol polymer matrix for specific uptake of creatinine, Anal. Bioanal. Chem. 407 (2015) 6747-6758.

21. N. Bereli, G. Ertürk, M.A. Tümer, R. Say, A. Denizli, Oriented immobilized anti-hlgG via $F_{c}$ fragment-imprinted PHEMA cryogel for IgG purification, Biomed. Chromatogr., 27 (2013) 599-607.

22. G. Ertürk, N. Bereli, M.A. Tümer, R. Say, A. Denizli, Molecularly imprinted cryogels for human interferon-alpha purification from human gingival fibroblast culture, J. Mol. Recognit., 26 (2013) 633-642.

23. W.L. Murphy, D.H. Kohn, D.J. Mooney, Growth of continuous bonelike mineral within porous poly (lactide-co-glycolide) scaffolds in vitro, J Biomed Mater Res., 8 (2000) 50-58.
24. A.R. Armiento, M.J. Stoddart, M. Alini, D. Eglin, Biomaterials for articular cartilage tissue engineering: Learning from biology, Acta Biomater., 65 (2018) 1-20.

25. E. Rosellini, N. Barbani, P. Giusti, G. Ciardelli, C. Cristallini, Molecularly imprinted nanoparticles with recognition properties towards a laminin $\mathrm{H}-\mathrm{Tyr}-\mathrm{Ile}-\mathrm{Gly}-\mathrm{Ser}-\mathrm{Arg}-\mathrm{OH}$ sequence for tissue engineering applications, Biomed. Mater., 5 (2010) 1-11.

26. S.M. DePorter, I. Lui, B.R. McNaughton, Programmed cell adhesion and growth on cell-imprinted polyacrylamide hydrogels, Soft Matter., 8 (2012) 10403-10408.

27. S. Aslıyüce, N. Bereli, L. Uzun, M.A. Onur, R. Say, A. Denizli, lon-imprinted supermacroporous cryogel, for in vitro removal of iron out of human plasma with beta thalassemia, Sep. Purif. Techn., 73 (2010) 243-249.

28. I.N. Mariana, E.W. Marissa, E.G. Manuela, R.L. Rui, L.G. Pedro, A.P. Nicholas, Molecularly Imprinted Intelligent Scaffolds for Tissue Engineering Applications, Tissue Eng. Part B., 23 (2016) 27-43

29. R. Gao, S. Zhao, Y. Hao, L. Zhang, X. Cui, D. Liu, Y. Tang, Facile and green synthesis of polysaccharide-based magnetic molecularly imprinted nanoparticles for protein recognition, RSC Adv., 5 (2015) 88436-88444.

30. D.M. Hawkins, D. Stevenson, S.M. Reddy, Investigation of protein imprinting in hydrogel-based molecularly imprinted polymers (HydroMIPs), Anal Chim Acta., 542 (2015) 61-65.

31. D.R. Kryscio, M.Q. Fleming, N.A. Peppas, Protein conformational studies for macromolecularly imprinted polymers, Macromol Biosci., 12 (2012) 1137-1144.

32. G. Vozzi, I. Morelli, F. Vozzi, C. Andreoni, E. Salsedo, A. Morachioli, P. Giusti, G. Ciardelli, SOFT-MI: A Novel Microfabrication Technique Integrating Soft-Lithography and Molecular Imprinting for Tissue Engineering Applications, Biotechnol. Bioengineer., 106, 5 (2010) 804-817.

33. T. Guo, Y. Xia, G. Hao, B. Zhang, G. Fu, Z. Yuan, B. He, J.K. Kennedy, Chemically modified chitosan beads as matrices for adsorptive separation of proteins by molecularly imprinted polymer, Carbohydr Polym., 62 (2005) 214-221.

34. Y.Q. Xia, T.Y. Guo, M.D. Song, B.H. Zhang, B.L. Zhang, Hemoglobin recognition by imprinting in semiinterpenetrating polymer network hydrogel based on poly-acrylamide and chitosan, Biomacromolecules., 6 (2005) 2601-2606

35. R. Dan, Y. Wang, L. Du, S. Du, M. Huang, S. Yang, M. Zhang, The synthesis of molecular imprinted chitosan-gels copolymerized with multiform functional monomers at three different temperatures and the recognition for the template ovalbumin, Analyst., 138 (2013) 3433-3443.

36. G. Criscenti, C.D. Maria, A. Longoni, C.A. Blitterswijk, H.A.M. Fernandes, G. Vozzi, L. Moroni, Soft-molecular imprinted electrospun scaffolds to mimic specific biological tissues, Biofabrication, 10 (2018) 045005, 1-9.

37. Y. Wu, X. Liu, J. Cui, M. Meng, J. Dai, C. Li, Y. Yan, Bioinspired synthesis of high-performance nanocomposite imprinted membrane by a polydopamine-assisted metal-organic method, J. Hazard. Mater., 323 (2017) 663-673.

38. I. Koç, G. Baydemir, E. Bayram, H. Yavuz, A. Denizli, Selective removal of $17 \beta$-estradiol with molecularly imprinted particle-embedded cryogel systems, J. Hazard. Mater., 192 (2011) 1819-1826.

39. H. Shaikh, M. Andaç, N. Memon, M.I. Bhanger, S.M. Nizamani, A. Denizli, Synthesis and characterization of molecularly imprinted polymer embedded composite cryogel discs: application for the selective extraction of cypermethrins from aqueous samples prior to GC-MS analysis, RSC Adv., 5 (2015) 26604-26615. 
40. G. Székely, I.B. Valtcheva, J.F. Kim, A.G. Livingston, Molecularly imprinted organic solvent nanofiltration membranes-Revealing molecular recognition and solute rejection behavior, React. Funct. Polym., 86 (2015) 215-224.

41. J.P. Fan, L. Li, Z.Y. Tian, C.F. Xie, F.T. Song, X.H. Zhang, J.H. Zhu, A novel free-standing flexible molecularly imprinted membrane for selective separation of synephrine in methanol-water media, J. Membrane Sci., 467 (2014) 13-22.

42. S. Akgönüllü, H. Yavuz, A. Denizli, Preparation of imprinted cryogel cartridge for chiral separation of I-phenylalanine, Artif. Cell. Nanomed. B., 45 (2017) 800-807.

43. X. Qiu, X.Y. Xu, Y. Liang, Y. Hua, H. Guo, Fabrication of a molecularly imprinted polymer immobilized membrane with nanopores and its application in determination of $\beta 2$ agonists in pork samples, J. Chromatogr. A., 1429 (2016) 79 85.

44. S. Aslıyüce, L. Uzun, A.Y. Rad, S. Ünal, R. Say, A. Denizli, Molecular imprinting based composite cryogel membranes for purification of anti-hepatitis B surface antibody by fast protein liquid chromatography, J. Chromatogr. B., 889 (2012) 95-102.

45. T. Li, L. Fan, Y. Wang, X. Huang, J. Xu, J. Lu, W. Xu, Molecularly imprinted membrane electrospray ionization for direct sample analyses, Anal. Chem., 89 (2017) 1453-1458.

46. N.X. Wang, H.A. von Recum, Affinity-based drug delivery, Macromol. Biosci., 11 (2011) 321-332.

47. D. Cunliffe, A. Kirby, C. Alexander, Molecularly imprinted drug delivery systems, Adv. Drug Deliv. Rev., 57 (2005) 18361853.

48. B. Sellergren, C.J. Allender, Molecularly imprinted polymers: A bridge to advanced drug delivery, Adv. Drug Deliv. Rev., 57 (2005) 1733-1741.

49. J.Z. Hilt, M.E. Byrne, Configurational biomimesis in drug delivery: molecular imprinting of biologically significant molecules, Adv. Drug Deliv. Rev., 56 (2014) 1599-1620.

50. V. Gemma, T.P. Judit, A. Fernando, Polymers and drug delivery dystems, Curr. Drug Deliv., 9 (2012) 367-394.

51. N. Sood, A. Bhardwaj, S. Mehta, A. Mehta, Stimuli-responsive hydrogels in drug delivery and tissue engineering, Drug Deliv., 23 (2016) 758-80.

52. C. Alvarez-Lorenzo, A. Concheiro, From drug dosage forms to intelligent drug delivery systems: a change of paradigm in: Alvarez- Lorenzo, C., Concheiro, A. (eds.), Smart materials for drug delivery, Cambridge: RSC, (2013) pp. 1-32.

53. C. Alvarez-Lorenzo, A. Concheiro, Molecularly imprinted polymers as components of drug delivery systems, in: Alvarez-Lorenzo, C., Concheiro, A. (eds.), Handbook of molecularly imprinted polymers, Shrewsbury, U.K., Smithers Rapra Publishing, (2013) pp. 309-49.

54. C. Alvarez-Lorenzo, C. Gonza'lez-Chomón. A. Concheiro, Molecularly imprinted hydrogels for affinity-controlled and stimuli responsive drug delivery, in: Alvarez-Lorenzo, C., Concheiro, A., Schneider, H.J., Shahinpoor, M. (eds.), Smart materials for drug delivery. Cambridge: RSC (2013) pp. 22860.

55. C. Alvarez-Lorenzo, F. Yañez-Gomez, A. Concheir, Modular biomimetic drug delivery systems, in: Dumitriu, S., Popa, V. (eds.) Polymeric materials, medicinal and pharmaceutical applications. Boca Raton, FL: CRC Press, (2013d) pp. 85-122.

56. A.Z. Shabi, Molecular imprinted polymers as drug delivery vehicles, Drug Delivery, 23 (2016) 2262-2271.

57. R. Suedee, The use of molecularly imprinted polymers for dermal drug delivery. Pharm. Anal. Acta. 4 (2013) 264.
58. G. Vlatakis, L.I. Andersson, R. Müller, K. Mosbach, Drug assay using antibody mimics made by molecular imprinting. Nature, 361 (1993) 645-647.

59. R. Suedee, C. Bodhibukkana, N. Tangthong, C. Amnuaikit, S. Kaewnopparat, T. Srichana, Development of a reservoir-type transdermal enantioselective-controlled delivery system for racemic propranolol using a molecularly imprinted polymer composite membrane. J. Control. Release, 129 (2018) 170178.

60. M.C. Norell, H.S. Andersson, I.A. Nicholls, 1998. Theophylline molecularly imprinted polymer dissociation kinetics: a novel sustained release drug dosage mechanism. J. Mol. Recognit., 11 (1998) 98-102.

61. C.J. White, M.K. McBride, K.M. Pate, A. Tieppo, M.E. Byrne, Extended release of high molecular weight hydroxypropyl methylcellulose from molecularly imprinted, extended wear silicone hydrogel contact lenses, Biomaterials, 32 (2011) 5698-5705.

62. Y. Zhang, C. Deng, S. Liu, J. Wu, Z. Chen, C. Li, W. Lu, Active targeting of tumors through conformational epitope imprinting, Angew. Chem., Int. Ed., 54 (205) 5157-5160.

63. X. Shen, J. S. Bonde, T. Kamra, L. Bülow, J.C. Leo, D. Linke, L. Ye, Bacterial imprinting at pickering emulsion interfaces, Angew. Chem. Int. Ed., 53 (2014) 10687-10690.

64. K. Çetin, A. Denizli, 5-Fluorouracil delivery from metalion mediated molecularly imprinted cryogel discs, Colloid. Surface. B. 126 (2015) 401-406.

65. P. Öncel, K. Çetin, A.A. Topçu, H. Yavuz, A. Denizli, Molecularly imprinted cryogel membranes for mitomycin C delivery, J. Biomat. Sci. Polym. E., 28 (2017) 519-531.

66. D. Türkmen, N. Bereli, M.E. Çorman, H. Shaikh, S. Akgöl, A. Denizli, Molecular imprinted magnetic nanoparticles for controlled delivery of mitomycin C, Artif. Cells Nanomed. Biotechnol., 42 (2014) 316-322.

67. M. Caka, T. Ceren, D.A. Uygun, M. Uygun, S. Akgöl, A. Denizli, Controlled release of curcumin from poly(HEMA-MAPA) membrane. Artif. Cells Nanomed. Biotechnol., 45 (2017) 426-431.

68. X.L. Liu, H.F. Yao, M.H. Chai, W. He, Y.P. Huang, Z.S. Liu, Green synthesis of carbon nanotubes-reinforced molecularly imprinted polymer composites for drug delivery of fenbufen, AAPS PharmSciTech., 19 (2018) 3995-3906.

69. M. Bakhshpour, H. Yavuz, A. Denizli, Controlled release of mitomycin C from PHEMAH-Cu(II) cryogel membranes, Artif. Cells Nanomed. Biotechnol. 46 (2018) 946-954.

70. F. Canfarotta, L. Lezina, A. Guerreiro, J. Czulak, A. Petukhov, A. Daks, K. Smolinska-Kempisty, A. Poma, S. Piletsky, N.A. Barlev, Specific drug delivery to cancer cells with doubleimprinted nanoparticles against epidermal growth factor receptor, Nano Letters 18 (2018) 4641-4646.

71. B.D. Meshram, A.K. Agrawal, S. Adil, S. Ranvir, K.K. Sande, Biosensor and its application in food and dairy industry: a review, Int. J. Curr. Microbiol. App. Sci. 7(2) (2018) 33053324

72. K. Haupt, and K. Mosbach, Molecularly imprinted polymers and their use in biomimetic sensors, Chem. Rev. 100 (2000) 2495-2504.

73. M. Nayak, A. Kotian, S. Marathe, D. Chakravortty, Detection of microorganisms using biosensors- A smarter way towards detection techniques, Biosens Bioelectron., 25 (2009) 661667.

74. V. Velusamy, K. Arshak, O. Korostynska, K. Oliwa, C. Adley, An overview of foodborne pathogen detection: In the prespective of biosensors, Biotechnol. Adv. 28 (2) (2010) 232-254. 
75. M.A. Arugula and A. Simonian, Novel trends in affinity biosensors: current challenges and perspectives, Meas. Sci. Technol., 25(3) (2014) 032001- 032022

76. L. Krejcova, P. Michalek, M.M. Rodrigo, Z. Heger, S. Krizkova M. Vaculovicova, D. Hynek, V. Adam, R. Kizek, Nanoscale virus biosensors: state of the art, Nanobiosens. Dis. Diagn. 4 (2015) 47-66

77. A. Singh, S. Poshtiban, S. Evoy, Recent advances in bacteriophage based biosensors for food-borne pathogen detection, Sensors, 13(2) (2013) 1763-1786.

78. O.S. Ahmad, T.S. Bedwell, C. Esen, A. Garcia-Cruz, S.A. Piletsky, 2018. Molecularly imprinted polymers in electrochemical and optical sensors, Trend Biotechnol. 37(3) (2018) 294-309.

79. J. Yasmin, M.R. Ahmed, B.K. Cho, Biosensors and their applications in food safety: a review, J. Biosystem. Eng., 41(3) (2016) 240-254.

80. Z. Zhao and $H$. Jiang, Enzyme-based electrochemical biosensors. (Eds.). Pier Andrea Serra, Biosensors, Intech, Croatia, (2010) 1-22.

81. C.M. Kisukuri and L.H. Andrade, Production of chiral compounds using immobilized cells as a source of biocatalysts. Org. Biomol. Chem. 40 (13) (2015) 10086 10107.

82. Y. Saylan, S. Akgönüllü, D. Çimen, A. Derazshamshir, N Bereli, F. Yılmaz, A. Denizli, Development of surface plasmon resonance sensors based on molecularly imprinted nanofilms for sensitive and selective detection of pesticides, Sensor. Actuator. B-Chem. 241 (2017) 446-454.

83. S. Akgönüllü, H. Yavuz, A. Denizli, SPR nanosensor based on molecularly imprinted polymer film with gold nanoparticles for sensitive detection of aflatoxin B1, Talanta, (2020) 121219

84. Y. Yanase, T. Hiragun, T. Yanase, T. Kawaguchi, K. Ishii, M Hide, Application of spr imaging sensor for detection of individual living cell reactions and clinical diagnosis of type I allergy, Allergol. Int. 62 (2013) 163-169.

85. A.M. Shrivastav, S.K. Mishra, B.D. Gupta, Fiber optic SPR sensor for the detection of melamine using molecular imprinting, Sensor. Actuator. B-Chem. 212 (2015) 404-410.

86. S.J.Y. Peng, B. Ning, J. Bai, Y. Liu, N. Zhang, Z. Gao, Surface plasmon resonance sensor based on molecularly imprinted polymer film for detection of histamine, Sensor Actuator B-Chem. 22 (2015) 15-21.

87. N. Cennamo, G. D’Agostino, M. Pesavento, L. Zeni, High selectivity and sensitivity sensor based on MIP and SPR in tapered plastic optical fibers for the detection of I-nicotine, Sensor. Actuator. B-Chem. 191 (2014) 529-536.

88. B.B. Prasad, D. Jauhari, M.P. Tiwari, Doubly imprinted polymer nanofilm-modified electrochemical sensor for ultra-trace simultaneous analysis of glyphosate and glufosinate, Biosens. Bioelectron. 59 (2014) 81-88.

89. Q. Han, X. Shen, W. Zhu, C. Zhu, X. Zhou, H. Jiang, Magnetic sensing film based on $\mathrm{Fe}_{3} \mathrm{O}$ @Au-GSH molecularly imprinted polymers for the electrochemical detection of estradiol Biosens. Bioelectron. 79 (2016) 180-186

90. L.Z. Wang and J. Zhang, Electrochemical sensor for levofloxacin based on molecularly imprinted polypyrrolegraphene-gold nanoparticles modified electrode, Sensor. Actuator. B-Chem. 192 (2014) 642-647

91. X. Kan, Z. Xing, A. Zhu, Z. Zhao, G. Xu, C. Li, H. Zhou, Molecularly imprinted polymers based electrochemical sensor for bovine hemoglobin recognition, Sensor. Actuator. B-Chem. 168 (2012) 395-401.
92. M.B. Gholivand, M. Torkashvand, A novel high selective and sensitive metronidazole voltammetric sensor based on a molecularly imprinted polymer-carbon paste electrode, Talanta. 84 (2011) 905-912.

93. Z. Yang, C. Zhang, Designing of MIP-based QCM sensor for the determination of $\mathrm{Cu}(\mathrm{II})$ ions in solution, Sensor. Actuator. B-Chem. 142 (2009) 210-215.

94. M. Hussain, K. Kotova, P.A. Lieberzeit, Molecularly imprinted polymer nanoparticles for formaldehyde sensing with QCM, Sensors,16 (2016) 1011.

95. K. Matsumoto, B.D.B. Tiu, A. Kawamura, R.C. Advincula, T. Miyata, QCM sensing of bisphenol A using molecularly imprinted hydrogel/conducting polymer matrix, Polymer Journal 48 (2016) 525-532.

96. F. Feng, J. Zheng, P. Qin, T. Hanb, D. Zhaoa, A novel quartz crystal microbalance sensor array based on molecularly imprinted polymers for simultaneous detection of clenbuterol and its metabolites, Talanta. 167 (2017) 94-102.

97. Battal, D., Akgönüllü, S., Yalçın, S.M., Yavuz, H., Denizli, A., Molecularly imprinted polymer based quartz crystal microbalance sensor system for sensitive and label-free detection of synthetic cannabinoids in urine, Biosens. Bioelectron., 111 (2018) 10-17.

98. W.J. Brittain and S. Minko, S., A structural definition of polymer brushes. J. Poly. Sci. Part A Poly. Chem. 45 (2007) 3505-3512.

99. G. Pan, Y. Zhang, X. Guo, C. Li, H. Zhang, An efficient approach to obtaining water-compatible and stimuliresponsive molecularly imprinted polymers by the facile surface-grafting of functional polymer brushes via RAFT polymerization. Biosens. Bioelectron. 26 (2010) 976-982.

100. P. Ma, Z. Zhou, J. Dai, L. Qin, X. Ye, X. Chen, J. He, A. Xie, Y. Yan $X$. Li, A biomimetic Setaria viridis-inspired imprinted nano adsorbent: green synthesis and application to the highly selective and fast removal of sulfamethazine. RSC Adv. 6 (2016) 9619-9630

101. J. Dai, Z. Zhou, Y. Zou, Z. Wei, X. Dai, C. Li, Y. Yan, Surface imprinted core-shell nanorod with ultrathin watercompatible polymer brushes for specific recognition and adsorption of sulfamethazine in water medium. J. Appl. Polym. Sci., 131(19) (2014) 1-11.

102. J. Dai, Y. Zou, Z. Zhou, X. Dai, J. Pan, P. Yu, T. Zou, Y. Yan, C. Li, Narrowly dispersed imprinted microspheres with hydrophilic polymer brushes for the selective removal of sulfamethazine. RSC Adv., 4 (2014) 1965-1973.

103. Y. Yang, H. Niu, H. Zhang, Direct and highly selective drug optosensing in real, undiluted biological samples with quantum-dot-labeled hydrophilic molecularly imprinted polymer microparticles. Appl. Mater. Interfaces, 8 (2016)15741-15749.

104. H. Niu, Y. Yang, H. Zhang, Efficient one-pot synthesis of hydrophilic and fluorescent molecularly imprinted polymer nano particles for direct drug quantification in real biological samples. Biosens. Bioelectron., 74 (2015) 440-446.

105. B. Prasad and A. Kumar, Development of molecularly imprinted polymer nanoarrays of $\mathrm{N}$-acryloyl-2mercaptobenzamide on a silver electrode for ultratrace sensing of uracil and 5-fluorouracil, J. Mater. Chem. B, 3 (2015) 5864-5876

106. D. Oliveira, R.C.S. Dias, M.R.P.F.N. Costa, Modeling RAFT Gelation and Grafting of Polymer Brushes for the Production of Molecularly Imprinted Functional Particles. Macromol. Symp., 370 (2016) 52-65. 
107. D. Oliveira, C.P. Gomes, R.C.S. Dias, M.R.P.F.N. Costa, Molecular imprinting of 5 -fluorouracil in particles with surface RAFT grafted functional brushes. React. Funct. Poly. 107 (2016) 35-45.

108. A.K. Patel, P.S. Sharma, B.B. Prasad, Electrochemical sensor for uric acid based on a molecularly imprinted polymer brush grafted to tetraethoxysilane derived sol-gel thin film graphite electrode. Mater. Sci. Engin. C, 29 (2009) 15451553.

109. S. Xua, H. Lua, L. Chen, Double water compatible molecularly imprinted polymers appliedas solid-phase extraction sorbent for selective preconcentration anddetermination of triazines in complicated water samples. J. Chromatogr. A, 1350 (2014) 23-29.
110. Y. Yang, Z. Wang, Z. Niu, H. Zhang, One-pot synthesis of quantum dot-labeled hydrophilic molecularly imprinted polymer nanoparticles for direct optosensing of folic acid in real, undiluted biological samples. Biosens. Bioelectron., 86 (2016) 580-587.

111. L. Zhao, F. Zhao, B. Zeng, Preparation of surface-imprinted polymer grafted with water-compatible external layer via RAFT precipitation polymerization for highly selective and sensitive electrochemical determination of brucine. Biosens. Bioelectron. 60 (2014) 71-76. 